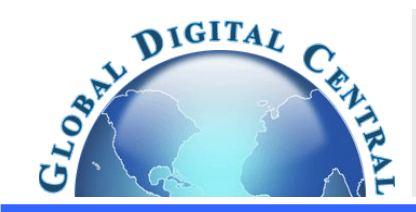

Frontiers in Heat and Mass Transfer

\title{
THE EFFECTS OF GAP SPACING RATIO ON FLOW STRUCTURE AND HEAT TRANSFER CHARACTERISTIC FOR THE V-ORIFICE IN THE SQUARE CHANNEL HEAT EXCHANGER
}

\author{
Amnart Boonloi ${ }^{\mathrm{a}}$ and Withada Jedsadaratanachai ${ }^{\mathrm{b}, *}$ \\ ${ }^{a}$ Department of Mechanical Engineering Technology, College of Industrial Technology, King Mongkut's University of Technology North Bangkok, \\ Bangkok 10800, Thailand \\ ${ }^{b}$ Department of Mechanical Engineering, Faculty of Engineering, King Mongkut's Institute of Technology Ladkrabang, Bangkok 10520, Thailand
}

\begin{abstract}
The variations of flow and heat transfer in the square channel heat exchanger inserted with various parameters of V-orifice are investigated numerically. The influences of flow directions (V-Downstream and V-Upstream), gap spacing ratios ( $\mathrm{g} / \mathrm{H}$ or $\mathrm{GR}=0,0.05,0.10,0.15,0.20,0.25$ and $0.30)$ and blockage ratios $(\mathrm{b} / \mathrm{H}$ or $\mathrm{BR}=0.05,0.10,0.15,0.25$ and 0.30$)$ on flow topology and heat transfer behavior are reported. The laminar flow regime with the Reynolds number in the range $100-2000$ is considered. The numerical results are presented in terms of flow and heat transfer structure in the heat exchanger channel. The thermal performance assessments in the square channel with V-orifice are also concluded. As the numerical results, the gap between the V-orifice and channel walls changes the flow and heat transfer mechanisms in the channel. The gap can reduce the friction loss in the channel and also helps to increase the turbulence of the flow. The optimum gap spacing ratio may help to increase the thermal performance of the square channel heat exchanger.
\end{abstract}

Keywords: V-orifice; square channel; heat exchanger; thermal performance; gap spacing ratio.

\section{INTRODUCTION}

The insertion of the vortex generator in the heat exchanger channel or tube is a technique for increase heat transfer rate and thermal efficiency of the heating system. The selection of the generator type depends on the application of the heat exchanger. The V-shape rib or baffle is a type of the vortex generator, which always inserts in the heat exchanger section to improve heat transfer rate. The V-baffle can induce the vortex flow, which disturbs the thermal boundary layer on the channel wall, that the reason for heat transfer rate and thermal performance enhancements. Many investigators had been reported about the augmentations on heat transfer rate and thermal efficiency by inserted the V-shaped baffle/rib in the heat exchanger channel [Boonloi (2014), Boonloi and Jedsadaratanachai (2014), Boonloi and Jedsadaratanachai (2016), Jedsadaratanachai and Boonloi (2014), Jedsadaratanachai et al. (2015), Kumar et al. (2017a), Kumar et al. (2017b), Kumar et al. (2016), Li et al. (2018), Promvonge (2010), Promvonge and Kwankaomeng (2010), Promvonge et al. (2012), Kumar et al. (2019)]. The researchers reported that the V-shaped baffle gives higher heat transfer rate and efficiency when compared with the other types of the vortex generators.

In the present investigation, the V-baffle is adapted like as the orifice called "V-orifice". The V-orifices are inserted in the heat exchanger square channel to augment the thermal efficiency of the test section. The gap between edges of the V-orifice and channel wall is varied. The optimum gap spacing may help to increase turbulent mixing of the tested fluid. The influences of the orifice height and orifice arrangement on heat transfer rate, pressure loss and thermal performance are also studied.

*Corresponding author.Email: kjwithad@kmitl.ac.th
The numerical investigation is selected to solve the present system. The numerical result can describe the heat transfer and flow configurations in the heating system. The understanding on flow and heat transfer mechanisms in the test section is an important knowledge, which can help to design the new type of the vortex generator and also helps to improve the thermo-hydraulic performance of the heat exchanger. However, it must sure that the computational domain has enough reliability to measure flow and heat transfer in the test section. Therefore, the computational domain for the heat exchanger channel inserted with the $\mathrm{V}$-orifice must be validated as the preliminary study.

\section{SQUARE CHANNEL WITH V-ORIFICE}

The computational domain for the square channel heat exchanger inserted with V-orifice is illustrated as Fig. 1. The height of the orifice is presented with "b", while the ratio between orifice height and channel height, $\mathrm{b} / \mathrm{H}$, is called "blockage ratio or BR". The blockage ratio of the system is varied in the range around $0.05-0.30$. "g" is the gap spacing between the $\mathrm{V}$-orifice and the channel walls. The ratio between gap spacing and channel height, $\mathrm{g} / \mathrm{H}$ or $\mathrm{GR}$, is varied in the range around $0-0.30$. The laminar flow regime at the inlet condition is considered for $\mathrm{Re}=100-2000$. The flow direction or V-orifice arrangement is separated into two directions; V-tip pointing downstream named "V-Downstream", while the opposite direction is called "V-Upstream". The flow attack angle of the V-orifice is fixed at $30^{\circ}$ for all investigated cases. The spacing between $\mathrm{V}$-orifice, $\mathrm{P}$, is set around $1 \mathrm{H}$ in all examples.

\section{ASSUMPTION, INITIAL CONDITION AND BOUNDARY CONDITION}

The numerical model for the heat exchanger square channel inserted with $\mathrm{V}$-orifice is developed under following assumption; 
- The flow and heat transfer are steady in three dimensions.

- The flow is laminar with the Reynolds number (at the inlet condition) around $100-2000$.

- The flow is incompressible condition.

- The convective heat transfer is considered, while the natural convection and radiation heat transfer are ignored.

- $\quad$ The body force and viscous dissipation are disregarded.
- $\quad$ The tested fluid is air with $300 \mathrm{~K}$. The thermal properties of the air are assumed to be constant at the average bulk mean temperature.

- $\quad$ No slip condition is applied for all sides of the channel walls and V-orifice.

- The channel wall is set with uniform temperature condition around $310 \mathrm{~K}$, while the V-orifice is set as insulator.

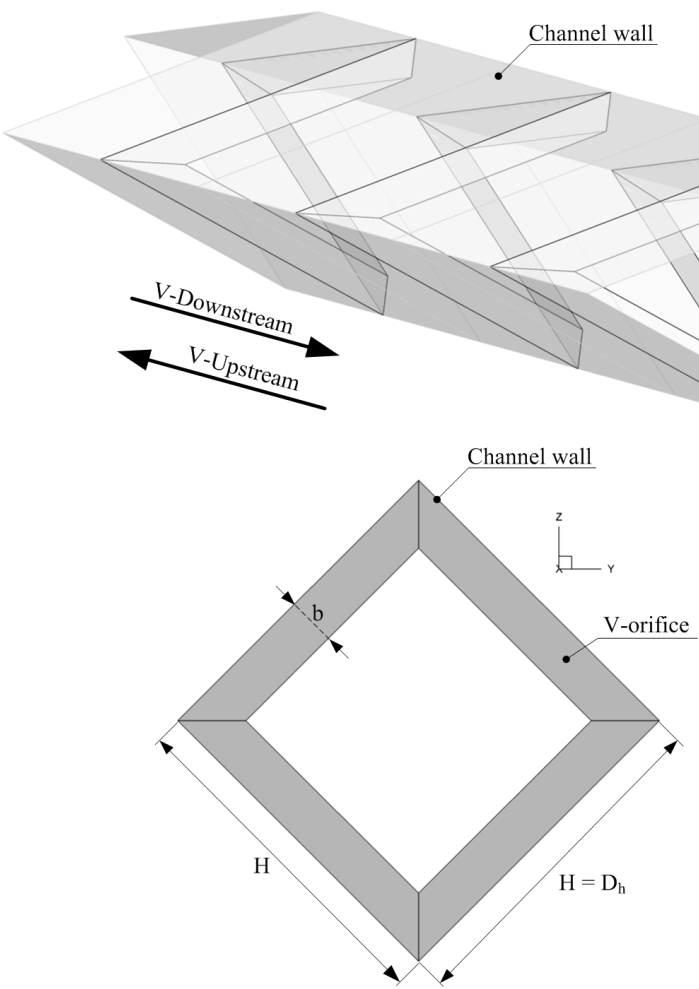

(a)
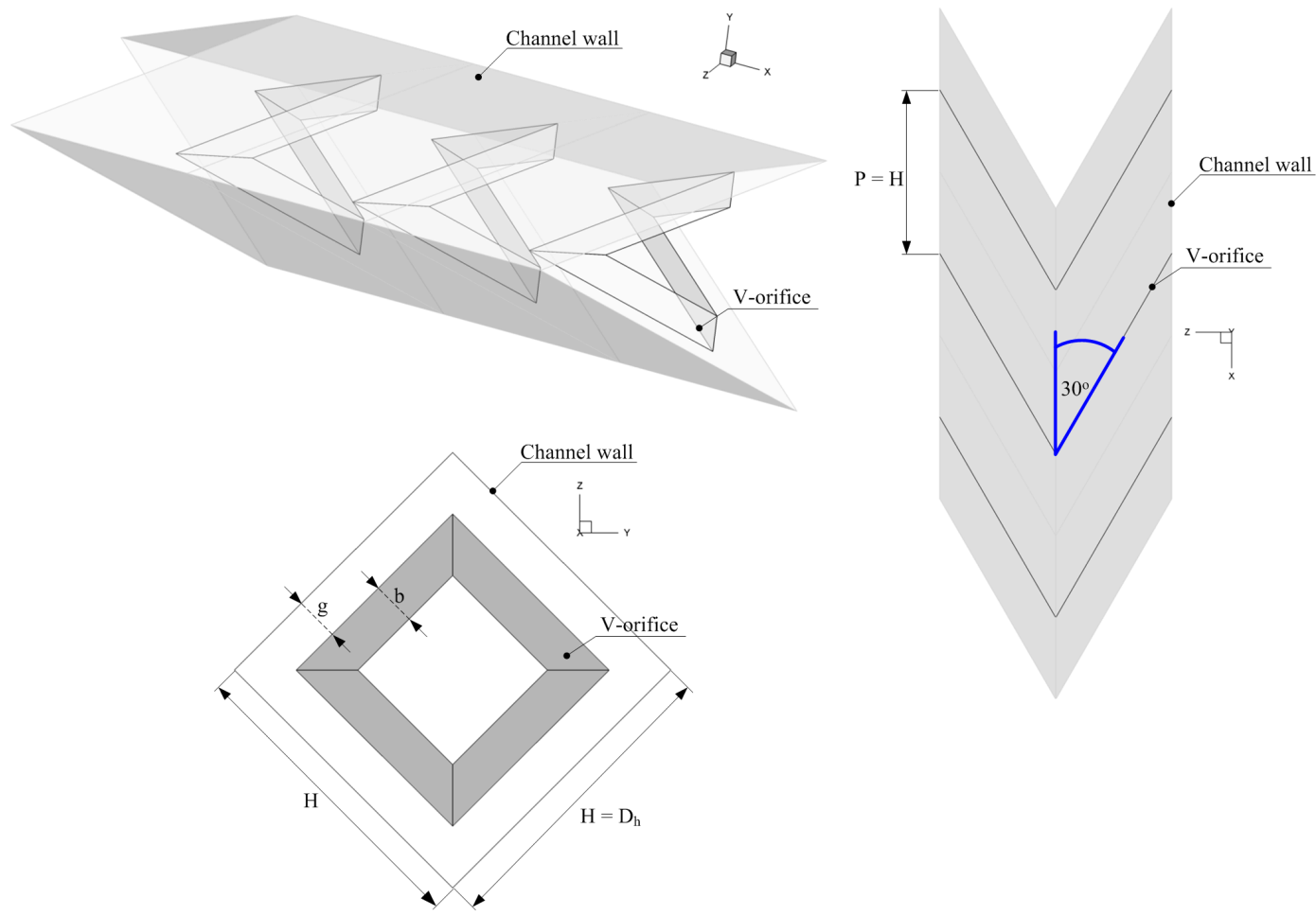

(b)

Fig. 1 Computational model for the square channel heat exchanger equipped with V-orifice of (a) no gap (GR $=0)$ and (b) with gap (GR $>0$ ). 
The boundary condition of the computational domain is concluded as Table 1.

Table 1 Boundary condition of the computational model.

\begin{tabular}{|l|l|}
\hline Zone & Boundary condition \\
\hline Inlet & Periodic condition \\
\hline Outlet & Periodic condition \\
\hline Channel wall & Uniform temperature around $310 \mathrm{~K}$ \\
\hline V-orifice & Uniform heat flux around $0 \mathrm{~W} / \mathrm{m}^{2}$ \\
\hline
\end{tabular}

\section{MATHEMATICAL FOUNDATION AND NUMERICAL METHOD}

The computational problem is solved by finite volume method (with SIMPLE algorithm). The computational domain is created under periodic concept (flow and heat transfer behavior repeats itself from one module to another). More detail of the periodic module was described by Patankar et al. (1998). The tested section is governed by the continuity, the Navier-Stokes equations and the energy equation as equations 1,2 and 3 , respectively.

Continuity equation:

$$
\frac{\partial}{\partial x_{i}}\left(\rho u_{i}\right)=0
$$

Momentum equation

$$
\frac{\partial\left(\rho u_{i} u_{j}\right)}{\partial x_{j}}=-\frac{\partial p}{\partial x_{i}}+\frac{\partial}{\partial x_{j}}\left[\mu\left(\frac{\partial u_{i}}{\partial x_{j}}+\frac{\partial u_{j}}{\partial x_{i}}\right)\right]
$$

Energy equation:

$\frac{\partial}{\partial x_{i}}\left(\rho u_{i} T\right)=\frac{\partial}{\partial x_{j}}\left(\Gamma \frac{\partial T}{\partial x_{j}}\right)$

the thermal diffusivity, $\Gamma$, is printed as follows:

$\Gamma=\frac{\mu}{\operatorname{Pr}}$

The continuity, momentum and energy equations are discretized by the power law scheme, power law scheme and QUICK scheme, respectively. The solutions are determined to be converged when the normalized residual values are less than $10^{-5}$ for all variables, but less than $10^{-9}$ only for the energy equation.

Due to the periodic boundary is set for the inlet and outlet of the computational domain. Therefore, the periodic conditions for flow are treated in the solution procedure as below description. More details about the periodic condition are described as Ref. (website: http://www.afs.enea.it/project/neptunius/docs/fluent/html/th/node18.ht m\#eq-periodic-p_April, 1, 2019)).

The pressure drop among the periodic module is written as equation 5 .

$\Delta p=p(\vec{r})-p(\vec{r}+\vec{L})=p(\vec{r}+\vec{L})-p(\vec{r}+2 \vec{L})=\ldots$

where, $\vec{r}$ and $\vec{L}$ are position vector and periodic length vector, respectively.

In the pressure-based solver, the local pressure gradient is separated into two sections;

1. The gradient of a periodic component, $\nabla \tilde{p}(\vec{r})$ and

2. The gradient of a linear-varying component, $\beta \frac{\vec{L}}{|\vec{L}|}$

$\nabla p(\vec{r})=\beta \frac{\vec{L}}{|\vec{L}|}+\nabla \tilde{p}(\vec{r})$

$\tilde{p}(\vec{r})$ represents the periodic pressure, while $\beta(\vec{r})$ is the linearlyvarying component of the pressure. The periodic pressure of the computational domain means the pressure left over after subtracting out the linearly-varying pressure. The linearly-varying component of the pressure effects for a force acting on the fluid in the momentum equation. Due to the $\beta$ is unknown, it must be iterated on until the mass flow rate is reached in the computational domain. For the SIMPLE algorithm, the correction of $\beta$ happens in the pressure correction step. The value of $\beta$ will be updated based on the difference among the setting mass flow rate and the actual value.

The air velocity is presented in term of the Reynolds number as equation 7. The pressure loss across the tested section is exposed with the friction factor (see equation 8), while the heat transfer rate is concluded with the local Nusselt number and average Nusselt number (see equations 9 and 10). The thermal performance of the heating system is summarized with the thermal enhancement factor as equation 11 .

$\operatorname{Re}=\frac{\rho \bar{u} D_{h}}{\mu}$

where, $\mathrm{D}_{\mathrm{h}}$ is hydraulic diameter of the square channel heat exchanger.

$$
\begin{aligned}
& f=\frac{(\Delta p / L) D_{h}}{\frac{1}{2} \rho \bar{u}^{2}} \\
& N u_{x}=\frac{h_{x} D_{h}}{k} \\
& N u=\frac{1}{L} \int N u_{x} \partial x
\end{aligned}
$$

The thermal enhancement factor (TEF) is the ratio of the heat transfer coefficient of an augmented surface, $h$, to that of a smooth channel, $\mathrm{h}_{0}$, at similar pumping power.

$T E F=\left.\frac{h}{h_{0}}\right|_{p p}=\left.\frac{N u}{N u_{0}}\right|_{p p}=\left(N u / N u_{0}\right) /\left(f / f_{0}\right)^{1 / 3}$

The $\mathrm{Nu}_{0}$ and $\mathrm{f}_{0}$ are the Nusselt number and friction factor for the smooth square channel, respectively.

\section{NUMERICAL VALIDATION AND GRID INDEPENDENCE}

The numerical validation and grid independence check are an important part for the numerical investigations. It must be sure that the computational domain has enough reliability to predict flow and heat transfer mechanisms in the test section. The validation of the computational domain is separated into two parts; smooth channel validation and grid independence. For the smooth channel validation, the Nusselt number and friction loss from the current investigation are compared with the values from the correlations. Fig. 2 reports the numerical validation of the smooth square channel with no V-orifice on heat transfer and pressure loss. As the figure, it is found that the deviations are around $\pm 0.5 \%$ and $\pm 2 \%$, respectively, for the Nusselt number and friction factor.

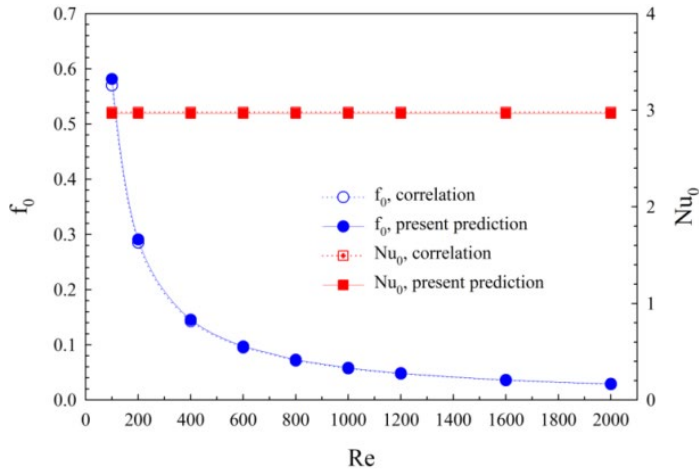

Fig. 2 Numerical validation of the smooth sqaure channel with no V-orifice. 
The grid independence for the computational domain is done by compared different numbers of grid cells. The cells around 120000 , 240000,360000 and 480000 for the numerical model $(\mathrm{BR}=0.15, \mathrm{GR}=$ 0.15 and V-Downstream) are compared by both flow and heat transfer. It is found that the augmentation of grid cell from 120000 to 240000 has no effect for both flow and heat transfer in the heating section. In conclusion, the creation model has enough credibility to measure flow and heat transfer characteristics in the tested section.

\section{NUMERICAL RESULT}

The mechanisms on flow and heat transfer in the tested section are reported. The thermal performance in terms of Nusselt number, friction factor and thermal enhancement factor is also concluded. The numerical results for the square channel heat exchanger inserted with $\mathrm{V}$-orifice are separated into five parts; general flow structure, effect of blockage ratio, effect of gap spacing ratio, effect of flow direction and thermal performance evaluation.

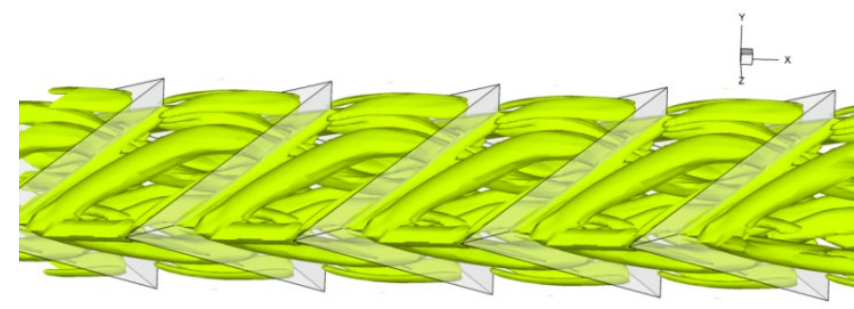

(a)

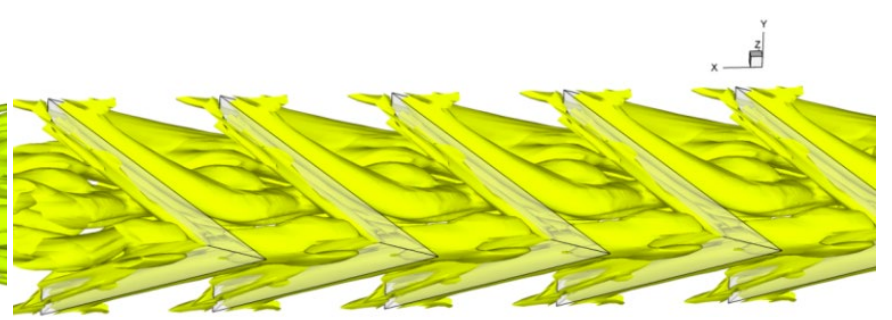

(b)

Fig. $3 \lambda_{2}$ iso-surface of the square channel heat exchanger equipped with V-orifice for (a) V-Downstream and (b) V-Upstream at BR $=0.20$, GR $=$ 0 and $\operatorname{Re}=1000$.

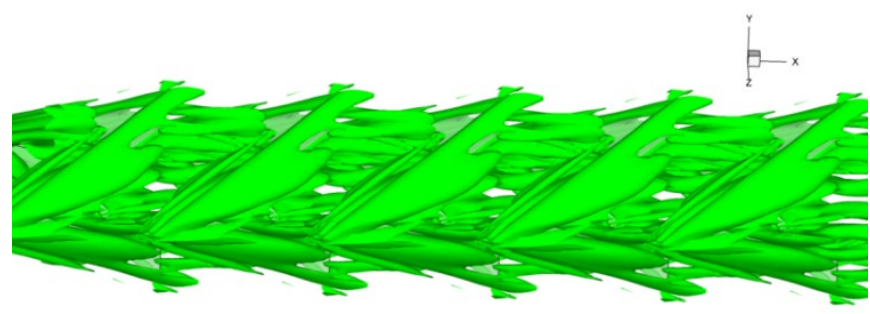

(a)

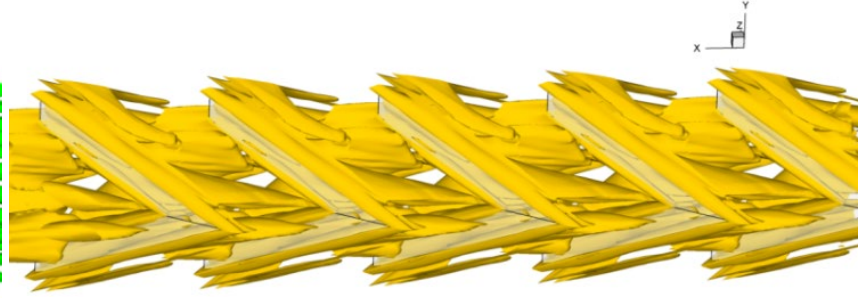

(b)

Fig. $4 \lambda_{2}$ iso-surface of the square channel heat exchanger equipped with V-orifice for (a) V-Downstream and (b) V-Upstream at BR $=0.20$, GR $=$ 0.10 and $\operatorname{Re}=1000$.

\subsection{General flow structure}

The flow topology in the test section is illustrated in terms of $\lambda_{2}$ isosurface. The $\lambda_{2}$ iso-surface is an indicator to check the core of the vortex flow in the heat exchanger square channel inserted with Vorifice. The Figs. 3, 4, 5 and 6 present the $\lambda_{2}$ iso-surface of the heat exchanger channel inserted with V-orifice at $\mathrm{GR}=0,0.10,0.20$ and 0.30 , respectively, with $\mathrm{BR}=0.20$ and $\mathrm{Re}=1000$. As the figures, the vortex flow appears through the test section for all investigated cases. The vortex strength decreases when enhancing the gap spacing value

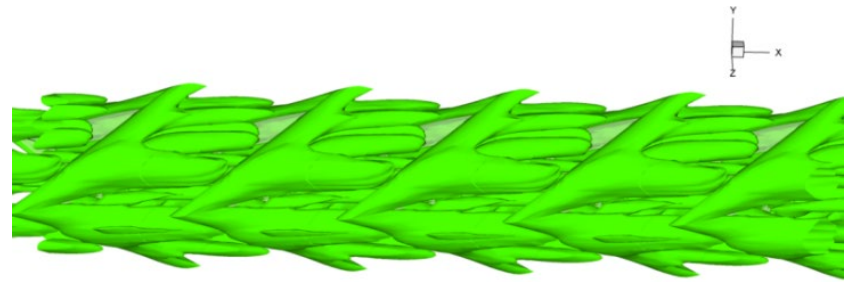

(a) for both arrangements. Some part of the fluid flows passes the gap when GR $>0$. This behavior may help to improve the heat transfer rate at behind the V-orifice and also helps to rise up the turbulent level of the flow mixing. The gap spacing assists to reduce the pressure loss in the tested channel. However, the high gap spacing ratio may bring to the extremely decrease of the heat transfer rate due to the reduction of the vortex strength. The heat transfer rate and thermal performance enhancements in the tested section will conclude at the thermal performance assessment part.

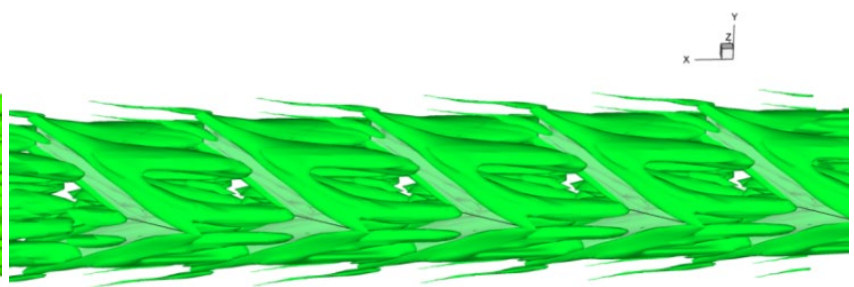

(b)

Fig. $5 \lambda_{2}$ iso-surface of the square channel heat exchanger equipped with V-orifice for (a) V-Downstream and (b) V-Upstream at BR $=0.20$, GR $=$ 0.20 and $\operatorname{Re}=1000$.

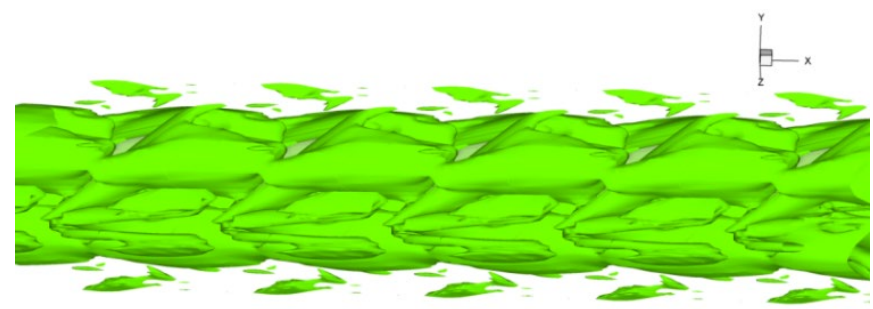

(a)

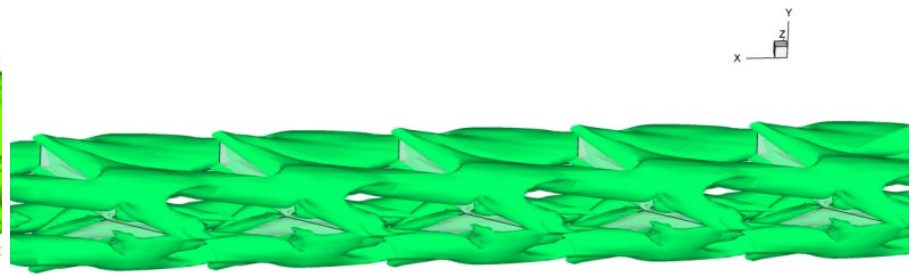

(b)

Fig. $6 \lambda_{2}$ iso-surface of the square channel heat exchanger equipped with V-orifice for (a) V-Downstream and (b) V-Upstream at BR $=0.20$, GR $=$ 0.30 and $\operatorname{Re}=1000$. 


\subsection{Effect of blockage ratio}

The effects of the orifice height in the square channel heat exchanger on heat transfer and flow structure are compared. The mechanisms in the test section are reported in terms of streamlines in transverse planes, temperature distributions in transverse planes and local Nusselt number distribution on the channel walls. Figs. 7a, b, c, d, e and f illustrate the streamlines in transverse planes for the square channel heat exchanger inserted with $\mathrm{V}$-orifice at $\mathrm{BR}=0.05,0.10,0.15,0.20,0.25$ and 0.30 , respectively, at $\mathrm{GR}=0.15, \mathrm{Re}=600$ and $\mathrm{V}$-Downstream arrangement. In general, the $\mathrm{V}$-orifice generates the vortex flow through the test channel for all flow blockage ratios. The four main vortex flows are found at the center of the channel, while the small vortices are detected at the corner of the channel. The symmetry configuration of the flow is found for the left and right part and also the upper-lower part due to the $\mathrm{V}$-orifice symmetry. The core of the flow has change due to the variations of the location in the channel and orifice height. The variation of the $\mathrm{V}$-orifice height also effects for the variation of the vortex strength. The increment of the orifice height helps to augment the strength of the vortex flow.

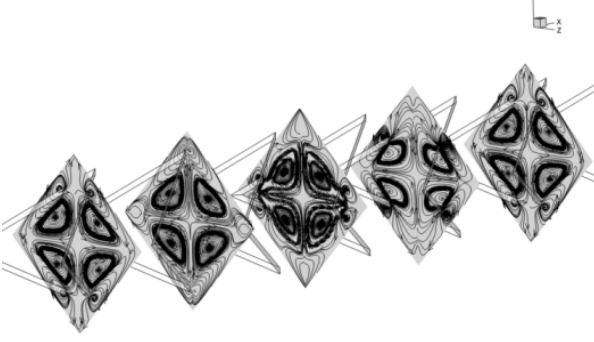

(a)

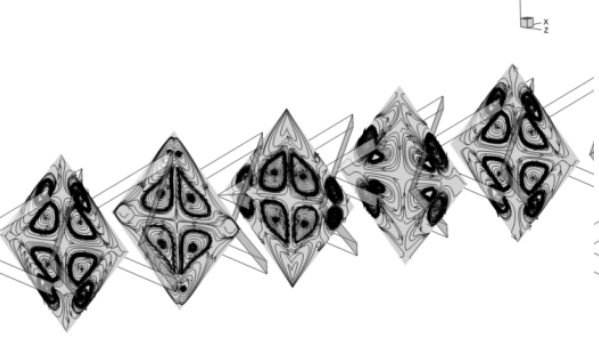

(b)

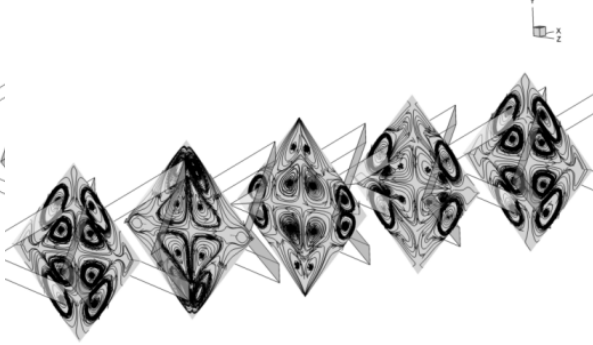

(c)

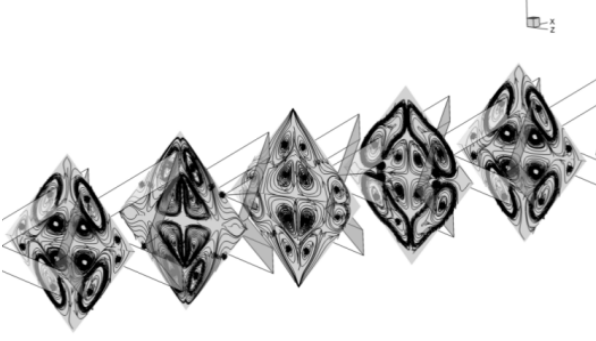

(d)

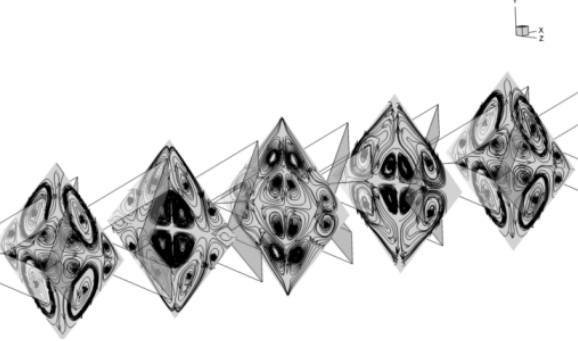

(e)

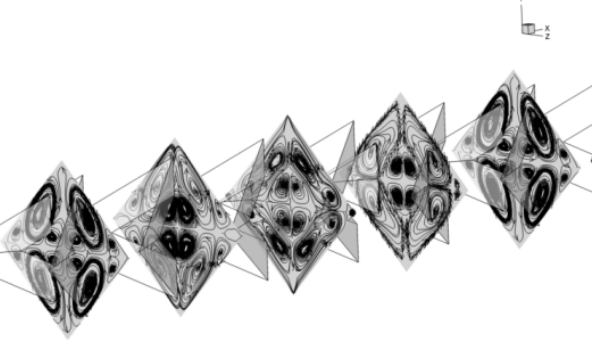

(f)

Fig. 7 Streamlines in transverse planes of the square channel heat exchanger equipped with V-orifice for (a) $B R=0.05$, (b) $B R=0.10$, (c) $B R=$ 0.15 , (d) $\mathrm{BR}=0.20$, (e) $\mathrm{BR}=0.25$ and (f) $\mathrm{BR}=0.30$ at $\mathrm{GR}=0.15$, V-Downstream and $\mathrm{Re}=600$.

Figs. $8 \mathrm{a}, \mathrm{b}, \mathrm{c}, \mathrm{d}$, e and $\mathrm{f}$ plot the temperature distribution in transverse planes of the square channel heat exchanger equipped with $\mathrm{V}$-orifice for $\mathrm{BR}=0.05,0.10,0.15,0.20,0.25$ and 0.30 , respectively, for $\mathrm{GR}=0.15, \mathrm{Re}=600$ and V-Downstream arrangement. Generally, the blue layer of the low temperature fluid is detected at the center of the channel, while the high temperature of the fluid, which is plotted with red layer, is found near the channel wall regime. The disturbance of the thermal boundary layer on the heat transfer surface is detected in all cases, especially, at $\mathrm{BR}=0.30$. The disturbance of the thermal boundary layer occurs due to the vortex flow, which is generated form the V-orifice. The high level of the vortex strength has directly effects for the disturbance of the thermal boundary layer. The $\mathrm{BR}=0.30$ gives the highest disturbance level of the thermal boundary layer, while the $\mathrm{BR}=0.05$ performs the opposite trend. The vortex flow in the test section also helps a better fluid mixing between the core of the channel (low temperature fluid) and the channel wall (high temperature fluid).

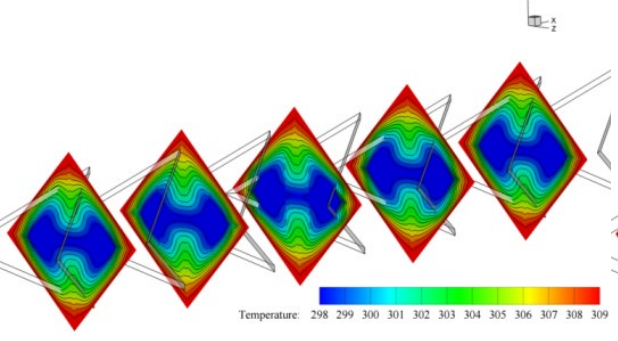

(a)

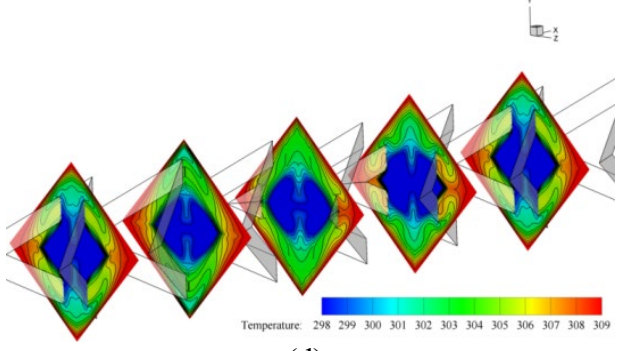

(d)

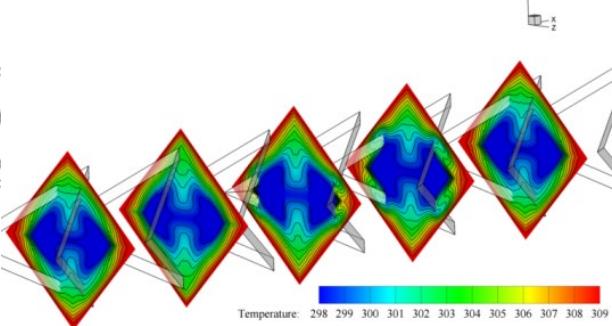

(b)

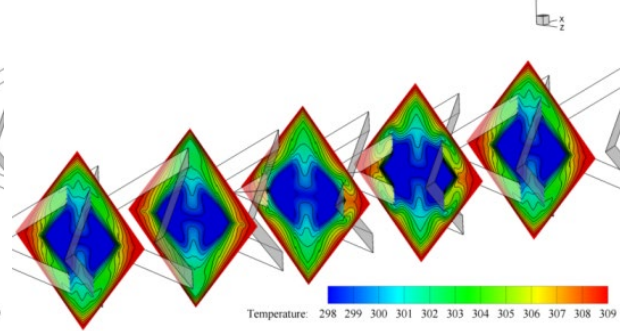

(c)

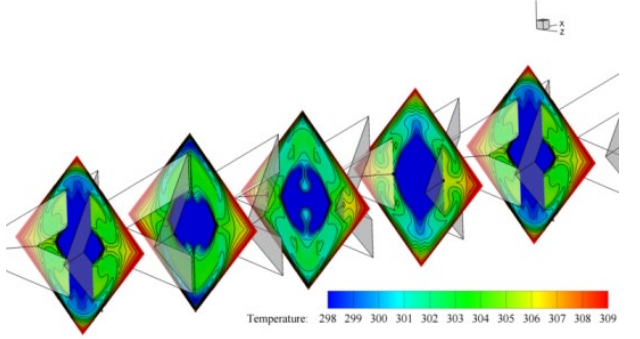

(f)

Fig. 8 Temperature distributions in transverse planes of the square channel heat exchanger equipped with $\mathrm{V}$-orifice for $(\mathrm{a}) \mathrm{BR}=0.05$, (b) $\mathrm{BR}=$ 0.10 , (c) $\mathrm{BR}=0.15$, (d) $\mathrm{BR}=0.20$, (e) $\mathrm{BR}=0.25$ and (f) $\mathrm{BR}=0.30$ at $\mathrm{GR}=0.15$, V-Downstream and $\mathrm{Re}=600$. 
Figs. 9a, b, c, d e and $\mathrm{f}$ report the local Nusselt number distributions on the channel wall for the heat exchanger square channel equipped with $\mathrm{V}$-orifice for $\mathrm{BR}=0.05,0.10,0.15,0.20,0.25$ and 0.30 , respectively, at $\mathrm{GR}=0.15, \mathrm{Re}=600$ and $\mathrm{V}$-Downstream arrangement. As the figures, the insertion of the $\mathrm{V}$-orifice in the channel gives higher heat transfer rate than the smooth square channel. The local Nusselt number clearly increases when augmenting the orifice height. The $\mathrm{BR}=$ 0.30 provides the highest heat transfer rate, while the $\mathrm{BR}=0.05$ performs the reverse result. This is because the $\mathrm{BR}=0.30$ of the Vorifice can generate the strongest vortex flow.

\subsection{Effect of gap spacing ratio}

The influences of the gap distance between the V-orifice and the channel walls on heat transfer and flow topology are compared in this part. Figs. 10a, b, c, d, e, f and $g$ depict the streamlines in transverse planes of the square channel heat exchanger equipped with $\mathrm{V}$-orifice at $\mathrm{GR}=0,0.05,0.10,0.15,0.20,0.25$ and 0.30 , respectively, at $\mathrm{BR}=$ $0.20, \mathrm{Re}=800$ and $\mathrm{V}$-Downstream arrangements. The four main vortex flows are found in all GR values. The small vortex flows near the channel wall are detected when GR $>0$. This is because some part of the flow passes the gap between $\mathrm{V}$-orifice and the channel wall.

Figs. 11a, b, c, d, e, f and g plot the temperature distribution in transverse planes of the square channel equipped with $\mathrm{V}$-orifice at $\mathrm{GR}=$ $0,0.05,0.10,0.15,0.20,0.25$ and 0.30 , respectively, at $\mathrm{BR}=0.20, \mathrm{Re}=$ 800 and $\mathrm{V}$-Downstream arrangement. In general, the better fluid mixing and the thermal boundary layer disturbance are found in all GR values. The blue layer (low fluid temperature) distributes from the center of the channel, while the red layer (high fluid temperature) near the channel wall is found to be thinner. The best fluid mixing is detected at GR $=0$ and 0.05 , while the opposite behavior is found at $\mathrm{GR}=0.15$.

Figs. 12a, b, c, d, e, f and $g$ report the local Nusselt number distributions on the channel walls, respectively, for $\mathrm{GR}=0,0.05,0.10$, $0.15,0.20,0.25$ and 0.30 , at $\mathrm{BR}=0.20, \mathrm{Re}=800$ and $\mathrm{V}$-Downstream placement. The heat transfer characteristic for the square channel inserted with V-orifice is found in nearly pattern. The best heat transfer rate is detected at $\mathrm{GR}=0$ and 0.05 , while the opposite result is found at $\mathrm{GR}=0.15$.

\subsection{Effect of flow direction}

The V-Downstream arrangement for the V-orifice is compared with the V-Upstream arrangement. Figs. 13a and b report the streamlines in transverse planes for the heat exchanger square channel equipped with $\mathrm{V}$-orifice at $\mathrm{GR}=0, \mathrm{BR}=0.20$ and $\mathrm{Re}=1000$ for the $\mathrm{V}$-Downstream and V-Upstream, respectively. In general, the V-orifice in the channel can produce the four main vortex flows through the test section for both arrangements. The difference of the placement leads to the variation of the flow structure. The V-Downstream orifice creates the counter vortex flow with common-flow-up, while the V-Upstream orifice performs the counter vortex flow with common-flow-down when considering at the lower pair of the vortex flow. Figs. 14a and $\mathrm{b}$ present the streamlines in transverse planes for the channel equipped with $\mathrm{V}$ Downstream and V-Upstream orifices, respectively, at $\mathrm{Re}=1000, \mathrm{BR}=$ 0.20 and $\mathrm{GR}=0.20$. The gap between the $\mathrm{V}$-orifice and the channel wall changes the flow structure in the test section. The four main vortex flows are detected at the center of the channel, while the small vortices are also found near the channel walls. The opposite flow rotation is detected when changes the V-orifice arrangement.

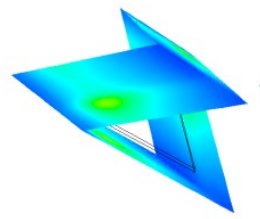

(a)

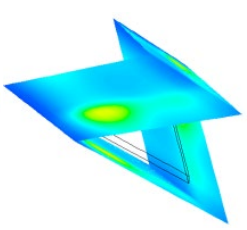

(b)

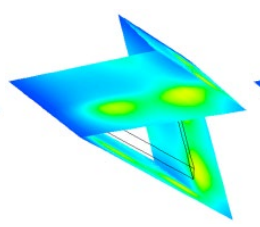

(c)

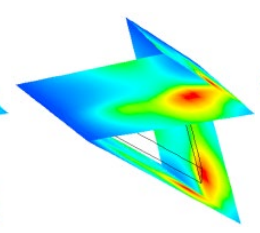

(d)

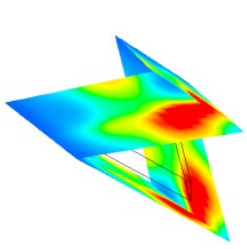

(e)

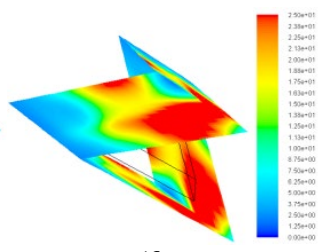

(f)

Fig. 9 Local Nusselt number of the square channel heat exchanger equipped with V-orifice for (a) $B R=0.05$, (b) $B R=0.10$, (c) $B R=0.15$, (d) $\mathrm{BR}=0.20$, (e) $\mathrm{BR}=0.25$ and (f) $\mathrm{BR}=0.30$ at $\mathrm{GR}=0.15, \mathrm{~V}$-Downstream and $\mathrm{Re}=600$.

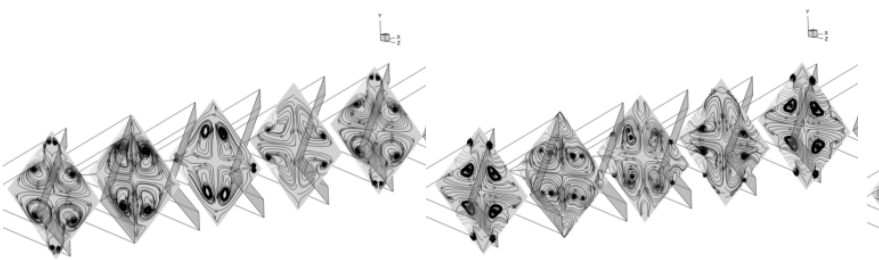

(a)

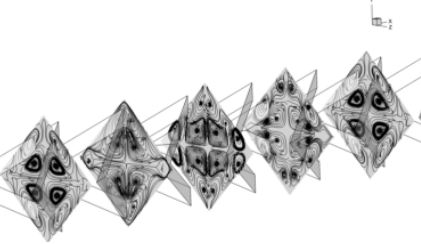

(c)

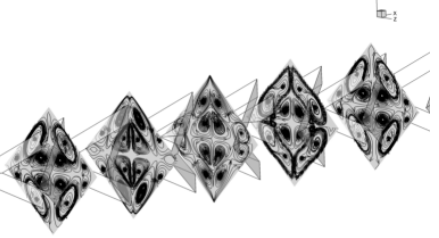

(d)

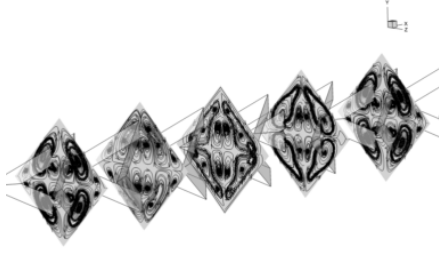

(e) (b)

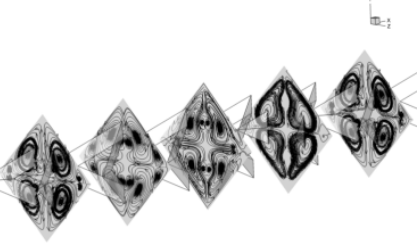

(f)

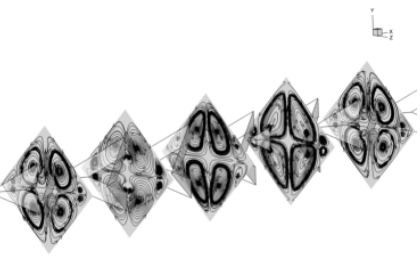

(g)

Fig. 10 Streamlines in transverse planes of the square channel heat exchanger equipped with V-orifice for (a) GR $=0$, (b) GR $=0.05$, (c) GR $=$ 0.10, (d) $\mathrm{GR}=0.15$, (e) $\mathrm{GR}=0.20$ and, (f) $\mathrm{GR}=0.25$ and (g) $\mathrm{GR}=0.30$ at $\mathrm{BR}=0.2, \mathrm{~V}$-Downstream and $\mathrm{Re}=800$.

The temperature distributions in transverse planes of the square channel equipped with V-orifice are depicted as Figs. 15a and b, respectively, for $\mathrm{V}$-Downstream and $\mathrm{V}$-Upstream arrangements at $\mathrm{Re}=$ $1000, \mathrm{GR}=0$ and $\mathrm{BR}=0.20$. The better fluid mixing is found for both arrangements. The thermal boundary layer disturbance on the channel walls is also detected for both arrangements, but the disturbance region is not similar. The heat transfer behavior is found to be in nearly trend for $\mathrm{GR}=0.20$ as depicted in Fig. 16 .

Figs. 17a and $\mathrm{b}$ plot the local Nusselt number distributions on the channel wall for $\mathrm{BR}=0.20, \mathrm{Re}=1000$ and $\mathrm{GR}=0$ of V-Downstream and V-Upstream placements, respectively, while the $\mathrm{GR}=0.20$ is illustrated as Fig. 18. The variation of the heat transfer location is detected when changing the $\mathrm{V}$-orifice placement and gap spacing ratio. 
For the GR $=0$, the peak of heat transfer is detected at the left-right part for V-Downstream arrangement, while found at the upper-lower part for V-Upstream arrangement. For the GR $=0.20$, the highest heat transfer regime is found at upper-lower part and left-right part for VDownstream and V-Upstream orifices, respectively.

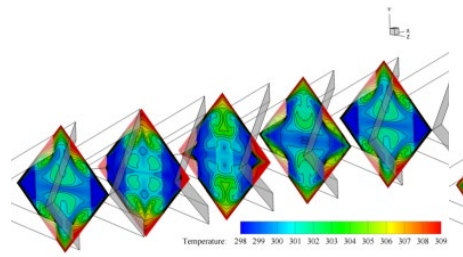

(a)

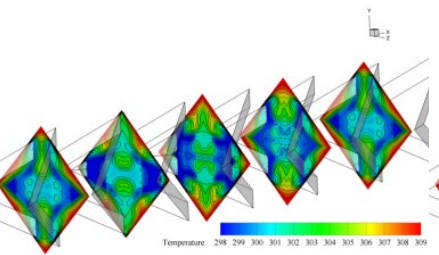

(b)

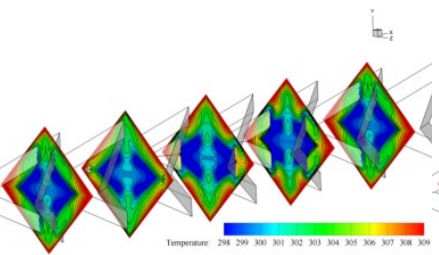

(c)

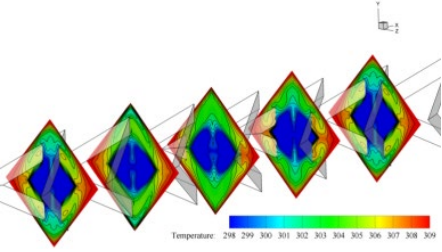

(d)

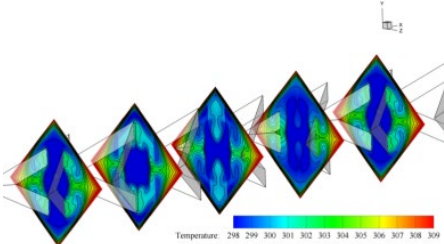

(e)

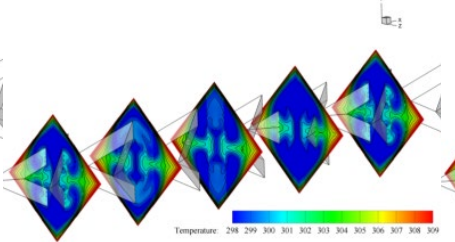

(f)

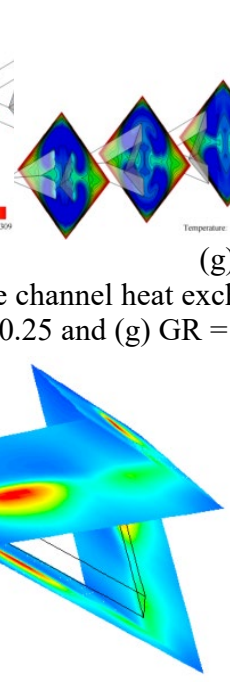

(c)

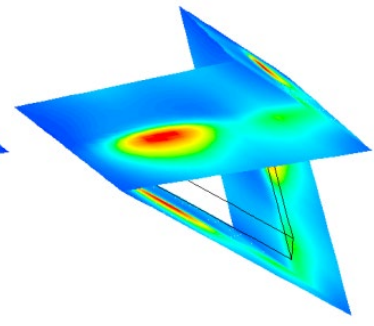

(f)

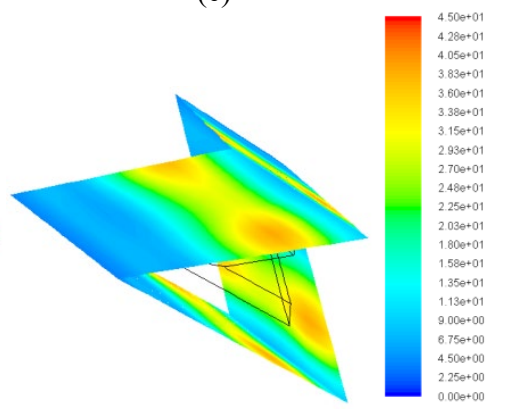

(g)

Fig. 12 Local Nusselt number of the square channel heat exchanger equipped with V-orifice for (a) GR $=0,(b) G R=0.05$, (c) $G R=0.10$, (d) $G R=$ 0.15 , (e) $\mathrm{GR}=0.20$ and, (f) $\mathrm{GR}=0.25$ and (g) $\mathrm{GR}=0.30$ at $\mathrm{BR}=0.2$, V-Downstream and $\mathrm{Re}=800$.

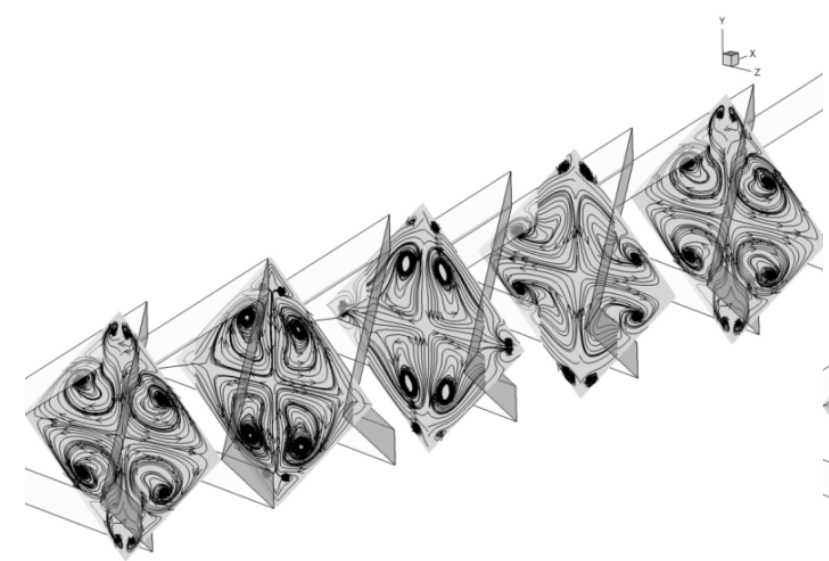

(a)

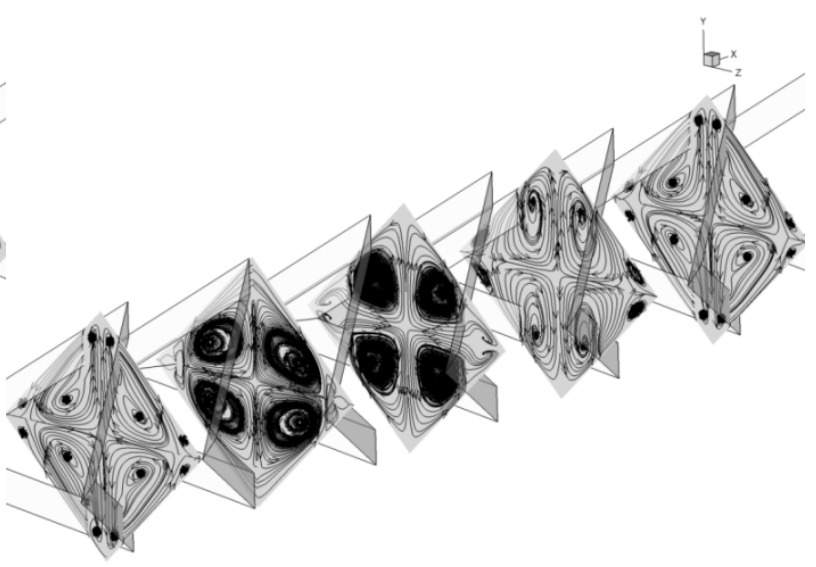

(b)

Fig. 13 Streamlines in transverse planes of the square channel heat exchanger equipped with V-orifice for (a) V-Downstream and (b) V-Upstream at $\mathrm{BR}=0.20, \mathrm{GR}=0, \mathrm{~V}$-Downstream and $\mathrm{Re}=1000$. 


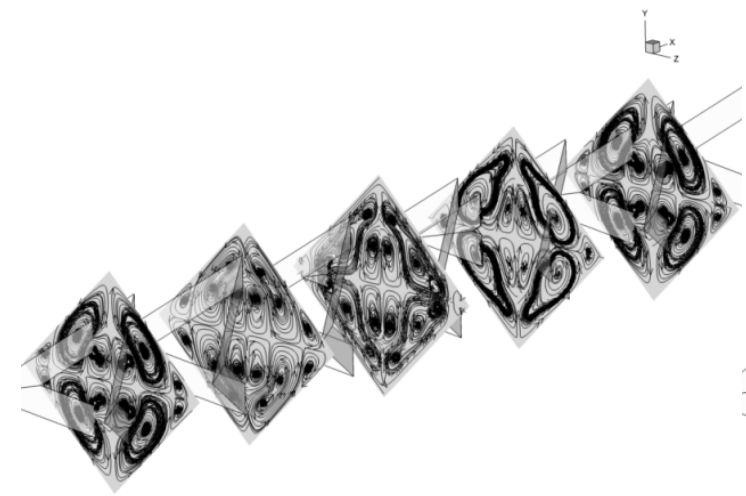

(a)

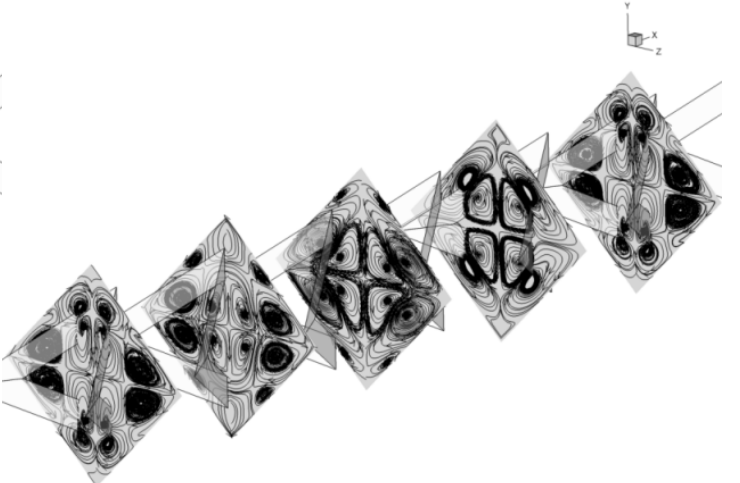

(b)

Fig. 14 Streamlines in transverse planes of the square channel heat exchanger equipped with V-orifice for (a) V-Downstream and (b) V-Upstream at $\mathrm{BR}=0.20, \mathrm{GR}=0.20, \mathrm{~V}$-Downstream and $\mathrm{Re}=1000$.

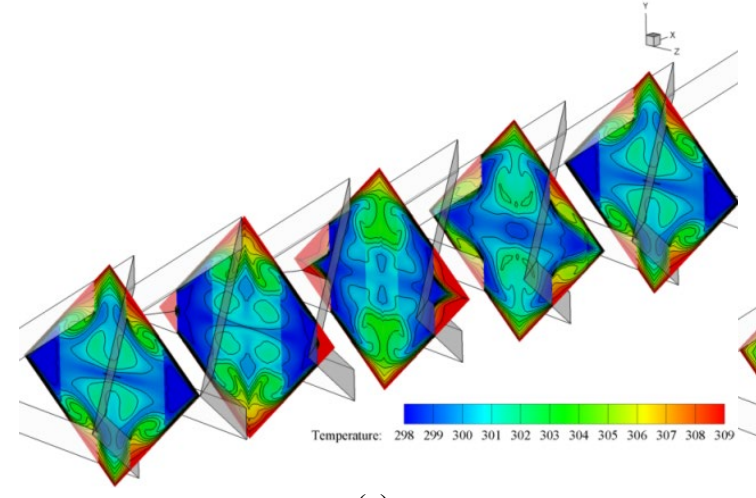

(a)

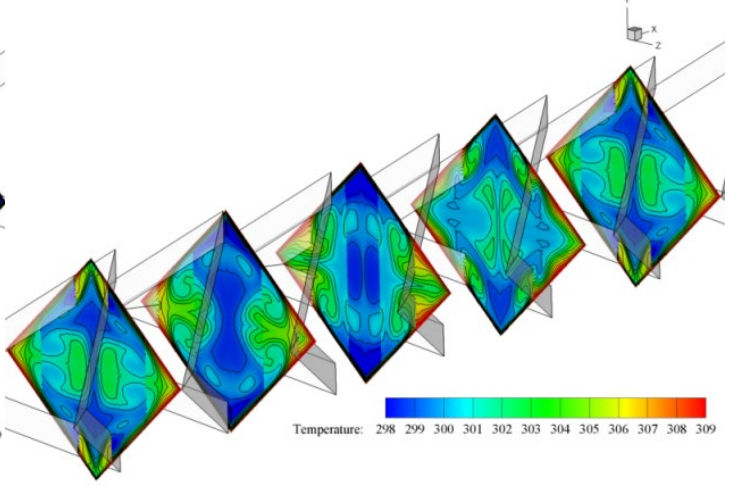

(b)

Fig. 15 Temperature distributions in transverse planes of the square channel heat exchanger equipped with V-orifice for (a) V-Downstream and (b) $\mathrm{V}$-Upstream at $\mathrm{BR}=0.20, \mathrm{GR}=0, \mathrm{~V}$-Downstream and $\mathrm{Re}=1000$

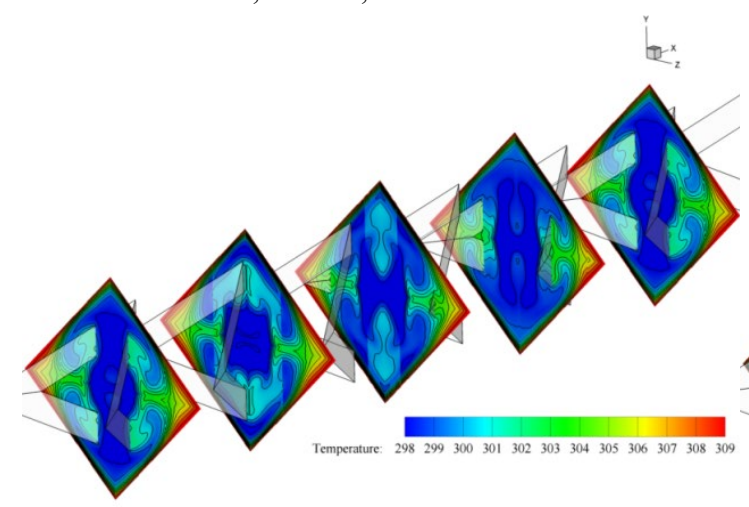

(a)

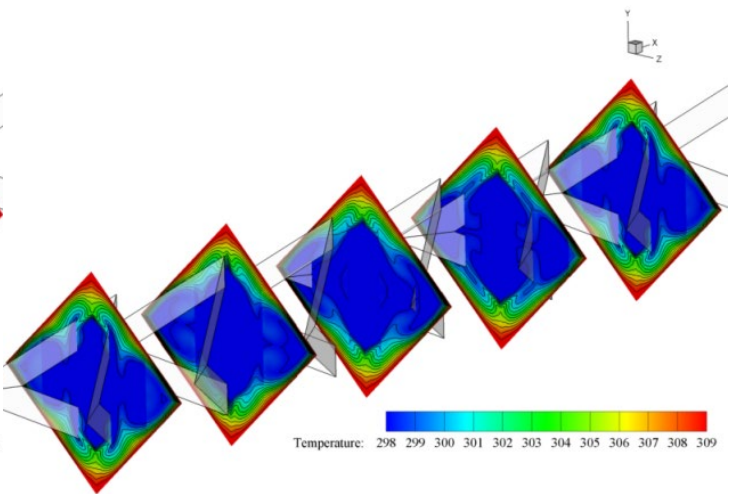

(b)

Fig. 16 Temperature distributions in transverse planes of the square channel heat exchanger equipped with V-orifice for (a) V-Downstream and (b) $\mathrm{V}$-Upstream at $\mathrm{BR}=0.20, \mathrm{GR}=0.20, \mathrm{~V}$-Downstream and $\mathrm{Re}=1000$.

\subsection{Thermal performance evaluation}

In this part, the heat transfer rate, pressure loss and thermal efficiency are concluded in forms of Nusselt number, friction factor and thermal enhancement factor, respectively. As Figs. 19a, b, c, d, e and f, the $\mathrm{Nu} / \mathrm{Nu}_{0}$ is plotted with the GR at various Re values for $\mathrm{V}$-Downstream arrangement for $\mathrm{BR}=0.05,0.10,0.15,0.20,0.25$ and 0.30 , respectively. Generally, the placement of the V-orifice in the heat exchanger square channel increases the heat transfer rate higher than the smooth square channel with no orifice ( $\mathrm{Nu} / \mathrm{Nu}$ o higher than unity). The heat transfer rate enhances when augmenting the Reynolds number for all BRs. The peak of heat transfer rate is found at GR $=0.05$ when $\mathrm{BR}>0.05$. The $\mathrm{Nu} / \mathrm{Nu}_{0}$ is around $1.00-5.02,1.00-6.57,1.00-$
$11.45,1.00-14.76,1.00-17.35$ and $1.00-19.68$, respectively, for BR $=0.05,0.10,0.15,0.20,0.25$ and 0.30 for $\mathrm{V}$-Downstream arrangement.

Figs. $20 \mathrm{a}, \mathrm{b}, \mathrm{c}, \mathrm{d}$, e and $\mathrm{f}$ report the variations of the $\mathrm{Nu} / \mathrm{Nu}_{0}$ with the GR at various Reynolds numbers for the V-Upstream arrangement of $\mathrm{BR}=0.05,0.10,0.15,0.20,0.25$ and 0.30 , respectively. The heat transfer rate increases when increasing the Reynolds number for all examples. The peak of heat transfer rate is detected at $\mathrm{GR}=0.30$ for $\mathrm{BR}=0.05$, while found at $\mathrm{GR}=0.05$ for $\mathrm{BR}=0.10$ and 0.30 . The $\mathrm{GR}=$ 0 (no gap) gives the highest heat transfer rate for $\mathrm{BR}=0.15-0.25$. The Nusselt number for $\mathrm{BR}=0.05,0.10,0.15,0.20,0.25$ and 0.30 is higher than the smooth square channel around $1.00-4.96,1.00-7.92,1.00-$ $11.99,1.00-14.23,1.00-14.84$ and $1.00-16.57$, respectively, for $\mathrm{V}$ Upstream orifice. 


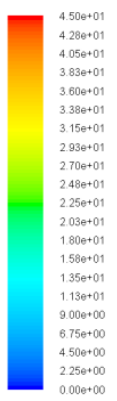

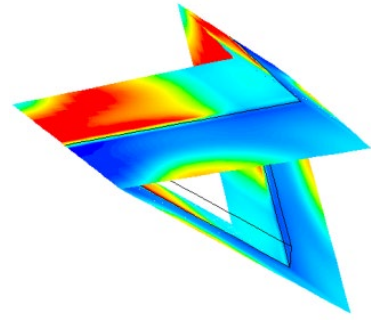

(a)

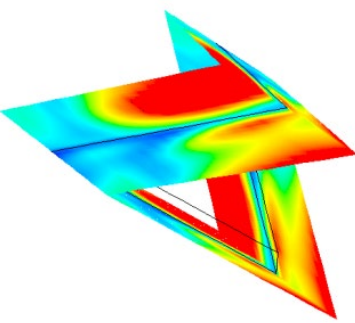

(b)

Fig. 17 Local Nusselt number of the square channel heat exchanger equipped with $\mathrm{V}$-orifice for (a) V-Downstream and (b) $\mathrm{V}$ Upstream at $\mathrm{BR}=0.20, \mathrm{GR}=0, \mathrm{~V}$-Downstream and $\mathrm{Re}=$ 1000 .

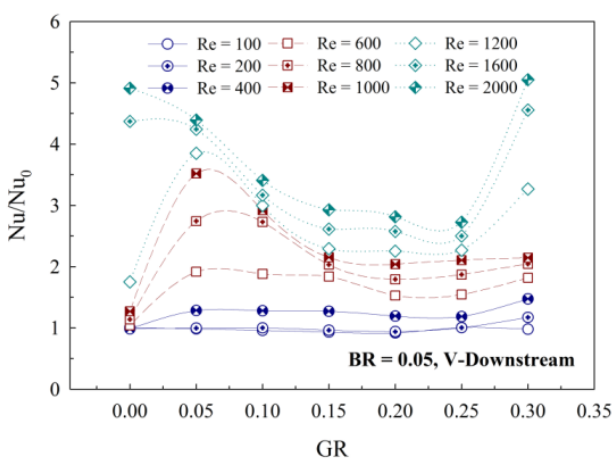

(a)

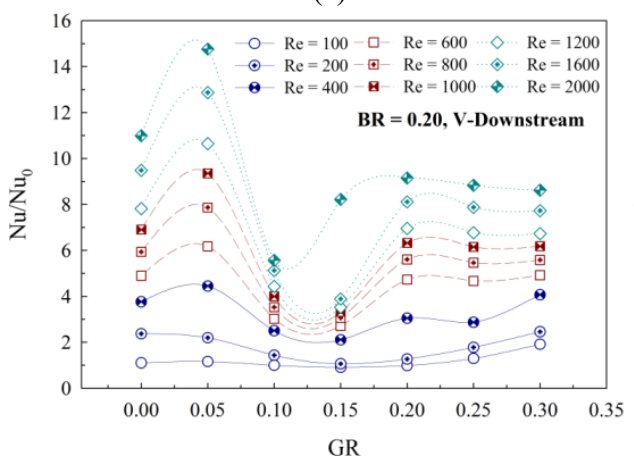

(d)

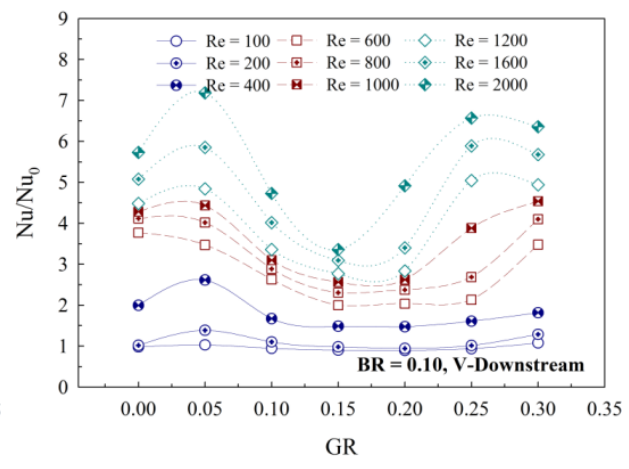

(b)

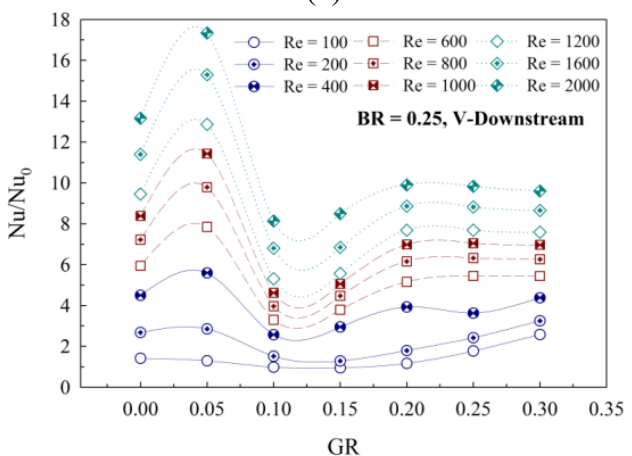

(e)

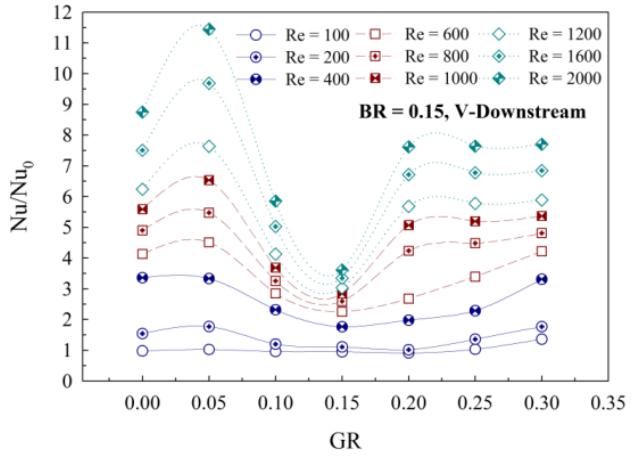

(c)

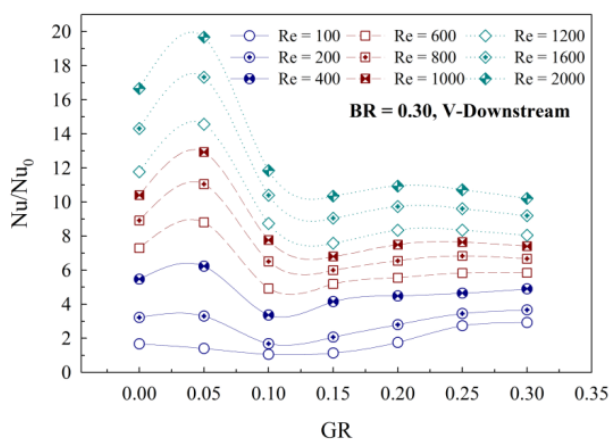

(f)

Fig. $19 \mathrm{Nu} / \mathrm{Nu}_{0}$ vs GR for V-Downstream of (a) $\mathrm{BR}=0.05$, (b) $\mathrm{BR}=0.10$, (c) $\mathrm{BR}=0.15$, (d) $\mathrm{BR}=0.20$, (e) $\mathrm{BR}=0.25$ and (f) $\mathrm{BR}=0.30$.

In comparison, the V-Downstream orifice gives the heat transfer rate higher than the $\mathrm{V}$-Upstream placement when $\mathrm{BR}>0.20$. For $\mathrm{BR}=$ $0.05-0.15$, the heat transfer rate for both arrangements is found to be in nearly value.

Figs. $21 \mathrm{a}, \mathrm{b}, \mathrm{c}, \mathrm{d}$, e and $\mathrm{f}$ plot the relation of the $\mathrm{f} / \mathrm{f}_{0}$ with the $\mathrm{GR}$ at various $\mathrm{Re}$ for $\mathrm{V}$-Downstream orifice at $\mathrm{BR}=0.05,0.10,0.15,0.20$, 0.25 and 0.30 , respectively. The friction loss enhances when augmenting the Reynolds number. The peak of friction loss is found at $\mathrm{GR}=0.10$ and 0.30 for $\mathrm{BR}=0.05$. For $\mathrm{BR}=0.10-0.20$, the highest pressure loss is found at GR $=0.05$. The pressure loss in the test section with $\mathrm{V}$-orifice is found to be highest at $\mathrm{GR}=0$ when $\mathrm{BR}>0.20$. The highest $\mathrm{f} / \mathrm{f}_{0}$ is around $6.09,14.61,30.49,55.56,102.20$ and 201.17, respectively, for $\mathrm{BR}=0.05,0.10,0.15,0.20,0.25$ and 0.30 at $\mathrm{V}$ Downstream placement.

Figs. $22 \mathrm{a}, \mathrm{b}, \mathrm{c}, \mathrm{d}$, e and $\mathrm{f}$ depict the $\mathrm{f} / \mathrm{f}_{0}$ versus $\mathrm{GR}$ with various Reynolds number for $\mathrm{V}$-Upstream placement. The highest of $\mathrm{f} / \mathrm{f}_{0}$ value for $\mathrm{BR}=0.05$ and 0.10 is found at $\mathrm{GR}=0.15$ and 0.10 , respectively, while detected at $\mathrm{GR}=0$ when $\mathrm{BR}>0.10$. The $\mathrm{f} / \mathrm{f}_{0}$ is found to be maximum around $7.27,15.49,31.47,71.91,150.04$ and 314.15, respectively, for $\mathrm{BR}=0.05,0.10,0.15,0.20,0.25$ and 0.30 , at $\mathrm{V}$ Upstream orifice. In comparison, the V-Downstream gives lower friction loss than the V-Upstream arrangement, especially, at BR $\geq$ 0.20 .

The relation of the TEF with GR for the square channel inserted with V-Downstream orifice is presented as Figs. 23a, b, c, d, e and f, respectively, for $\mathrm{BR}=0.05,0.10,0.15,0.20,0.25$ and 0.30 . The maximum TEF is found at $\mathrm{GR}=0.05$, except for $\mathrm{BR}=0.05$, which the peak of TEF is detected at GR $=0$. The optimum TEF of the VDownstream arrangement is around 3.36, 2.94, 3.66, 3.87, 3.80 and 3.62 for $\mathrm{BR}=0.05,0.10,0.15,0.20,0.25$ and 0.30 , respectively.

The plot of the TEF versus GR with various Reynolds numbers is presented as Figs. 23a, b, c, d, e and f for V-Upstream orifice in the square channel. The maximum $\mathrm{TEF}$ is found at $\mathrm{GR}=0$ for $\mathrm{BR}=0.05$, while detected at $\mathrm{GR}=0.05$ for $\mathrm{BR}=0.10$. For $\mathrm{BR}=0.15$ and 0.20 , the $\mathrm{GR}=0$ provides the highest TEF. The optimum $\mathrm{TEF}$ for $\mathrm{BR}=0.25$ and 0.30 is detected at GR $=0.05$ and 0.30 , respectively. The peak of TEF is around $3.31,3.25,3.80,3.42,2.89$ and 2.94 , respectively, for $\mathrm{BR}=$ $0.05,0.10,0.15,0.20,0.25$ and 0.30 of V-Upstream arrangement. 


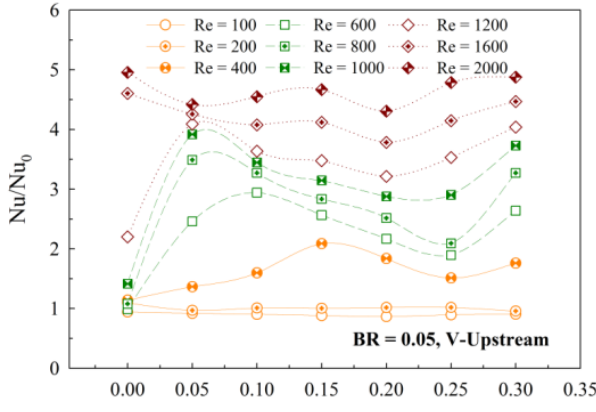

(a)

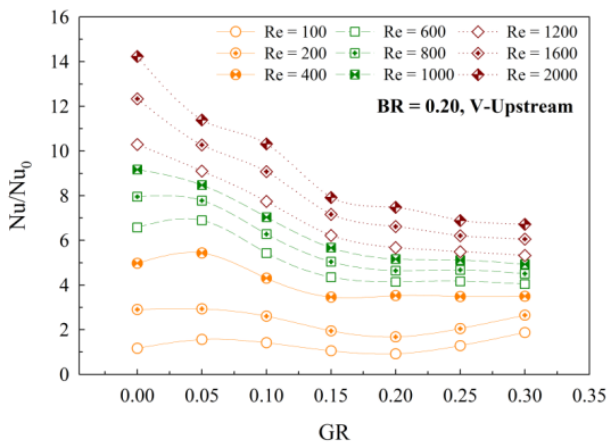

(d)

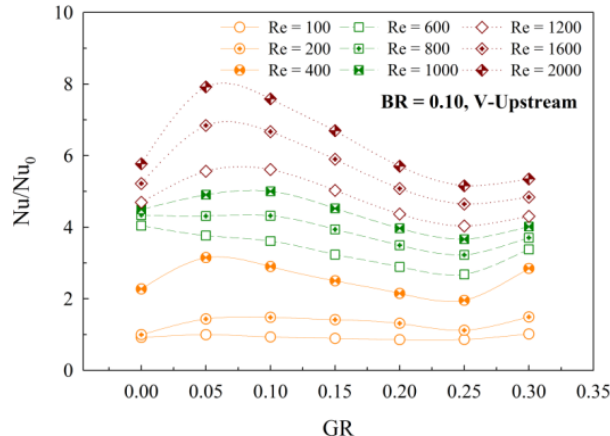

(b)

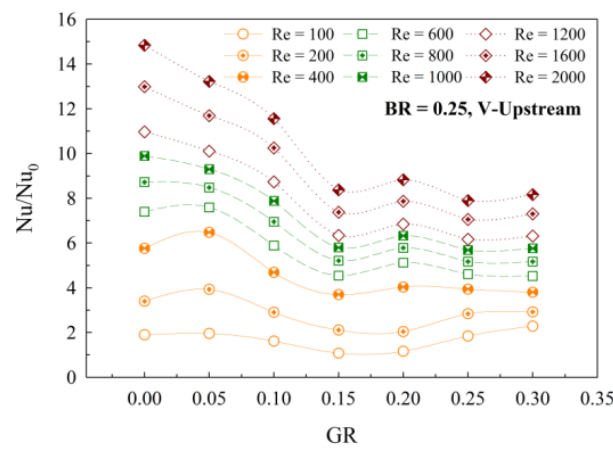

(e)

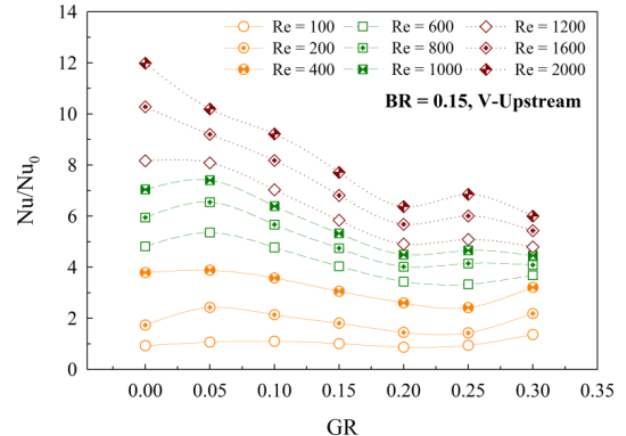

(c)

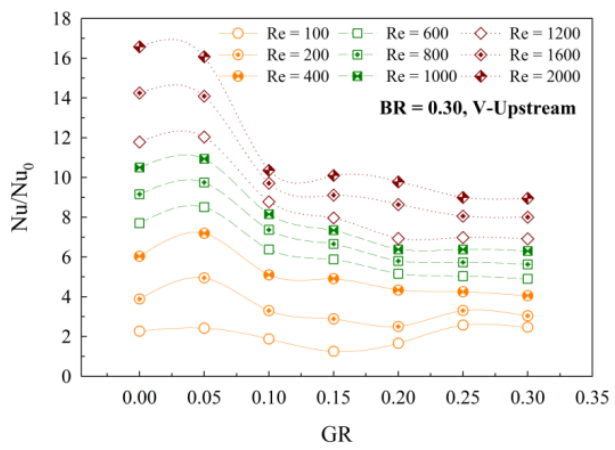

(f)

Fig. $20 \mathrm{Nu} / \mathrm{Nu}_{0}$ vs GR for $\mathrm{V}-$ Upstream of (a) $\mathrm{BR}=0.05$, (b) $\mathrm{BR}=0.10$, (c) $\mathrm{BR}=0.15$, (d) $\mathrm{BR}=0.20$, (e) $\mathrm{BR}=0.25$ and (f) $\mathrm{BR}=0.30$.

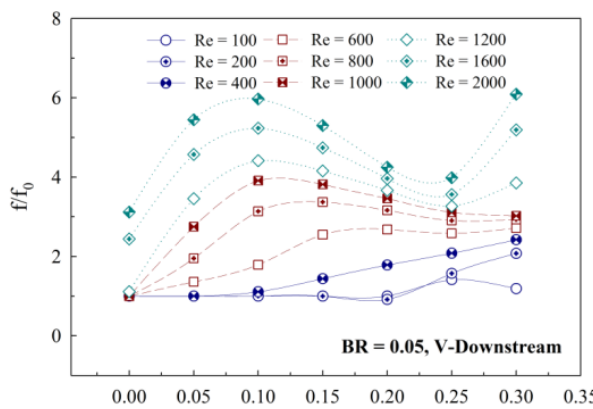

(a)

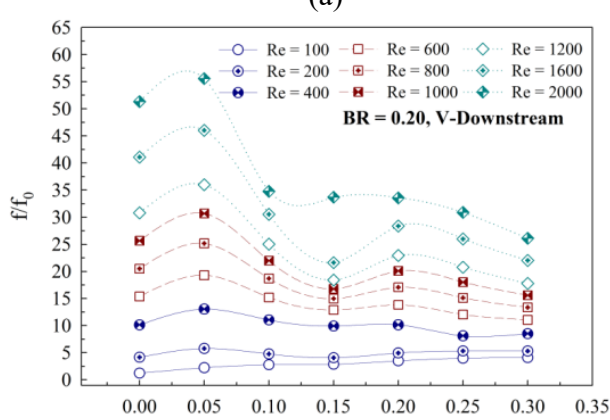

GR

(d)

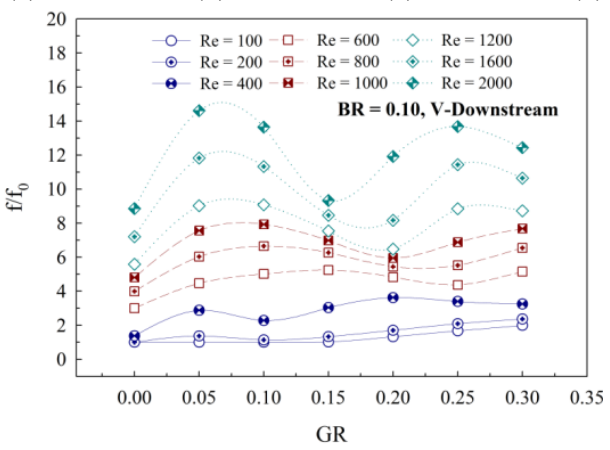

(b)

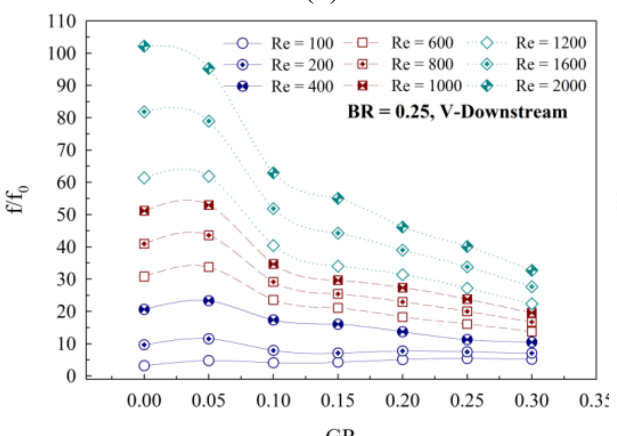

(e)

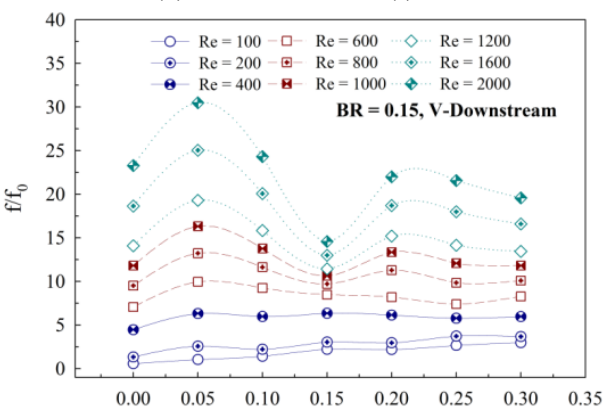

(c)

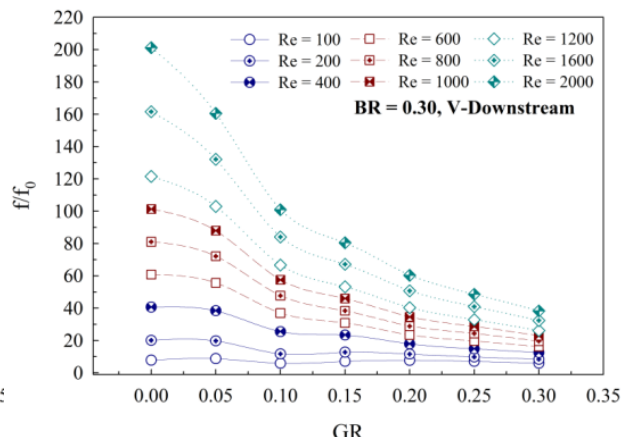

(f)

Fig. $21 \mathrm{f} / \mathrm{f}_{0}$ vs GR for V-Downstream of (a) $\mathrm{BR}=0.05$, (b) $\mathrm{BR}=0.10$, (c) $\mathrm{BR}=0.15$, (d) $\mathrm{BR}=0.20$, (e) $\mathrm{BR}=0.25$ and (f) $\mathrm{BR}=0.30$.

\section{CONCLUSION}

Numerical predictions on heat transfer, pressure loss and thermal performance in the heat exchanger square channel equipped with Vorifice are presented. The variations of orifice height, gap spacing and orifice placement are investigated for the Reynolds number around 100 -2000 (laminar regime). The numerical results in the test section are reported in terms of flow and heat transfer mechanisms. The thermal performance in the heating channel is also concluded. As the numerical result, the major finding can conclude as follows;

The V-orifice in the square channel can create the vortex flow through the test section for all cases. The vortex flow will disturb the thermal boundary layer on the heat transfer surfaces that effects for the augmentation of the heat transfer rate. 


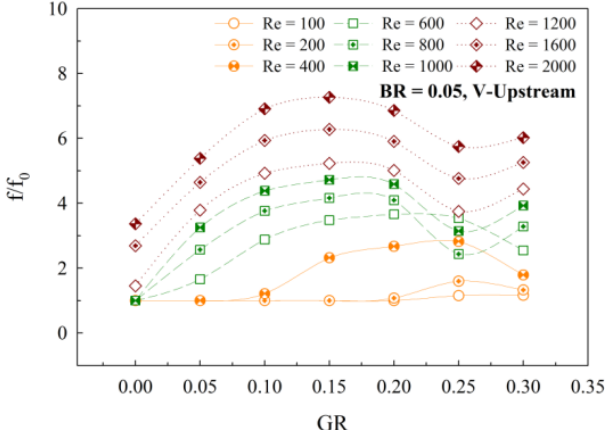

(a)

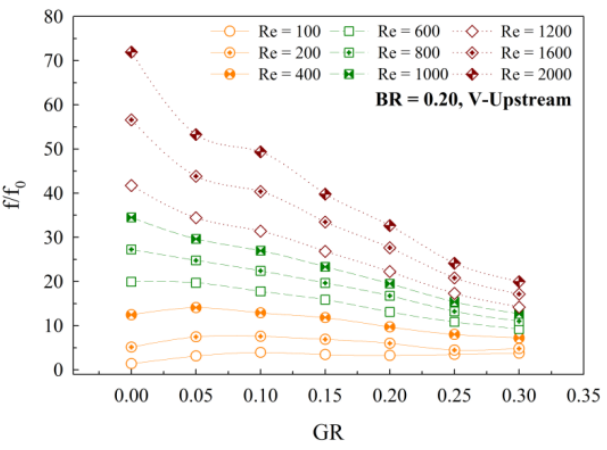

(d)

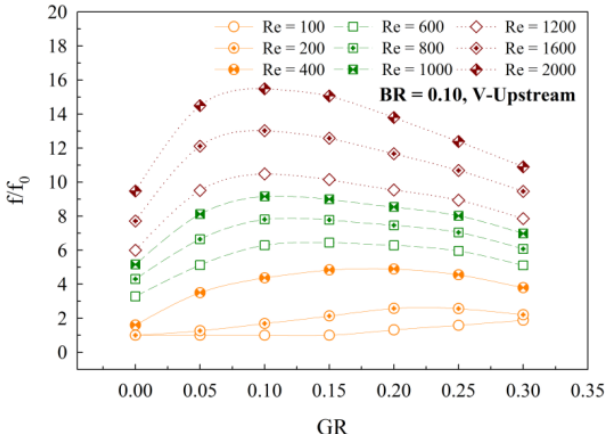

(b)

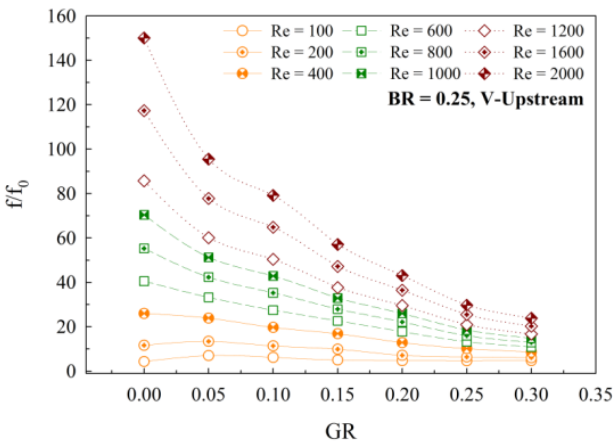

(e)

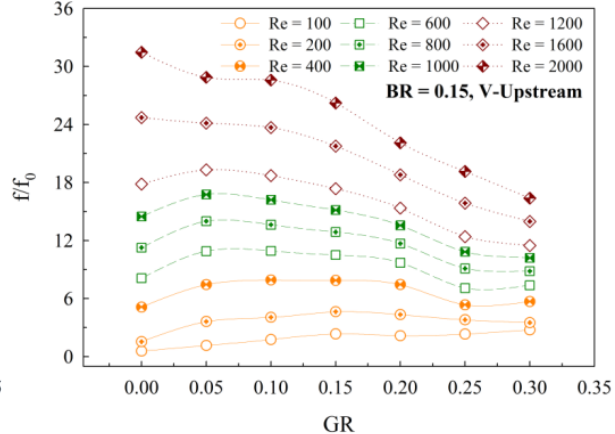

(c)

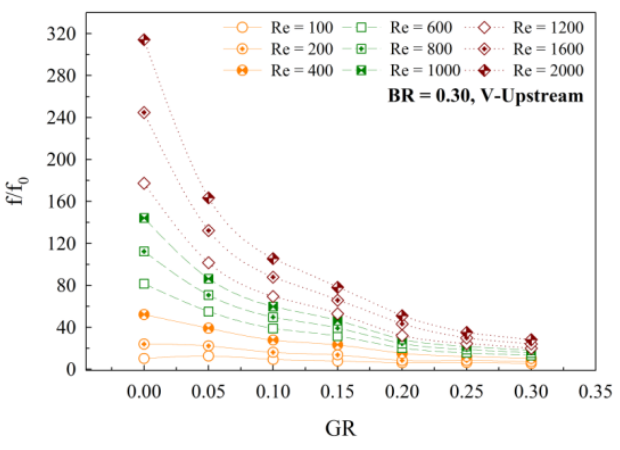

(f)

Fig. $22 \mathrm{f} / \mathrm{f}_{0}$ vs GR for V-Upstream of (a) $\mathrm{BR}=0.05$, (b) $\mathrm{BR}=0.10$, (c) $\mathrm{BR}=0.15$, (d) $\mathrm{BR}=0.20$, (e) $\mathrm{BR}=0.25$ and (f) $\mathrm{BR}=0.30$.

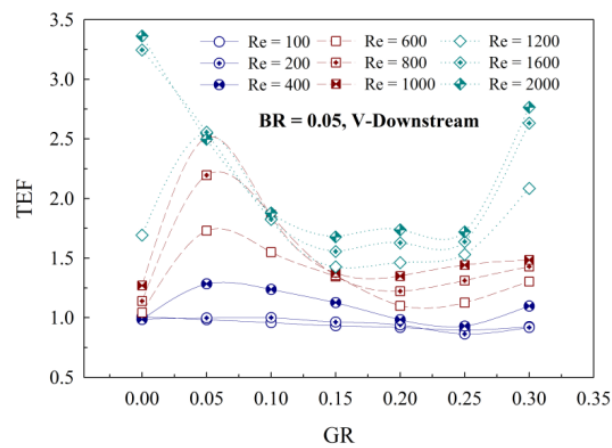

(a)

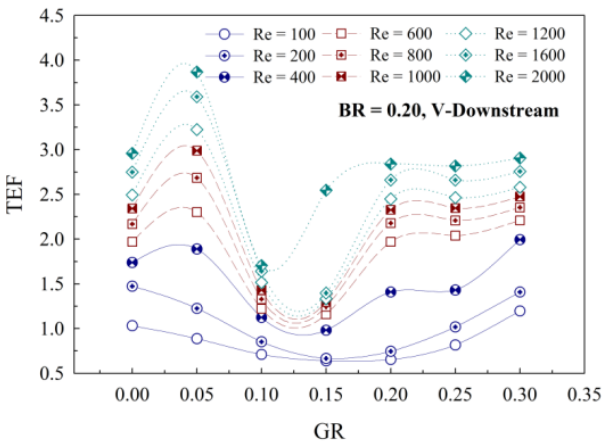

(d)

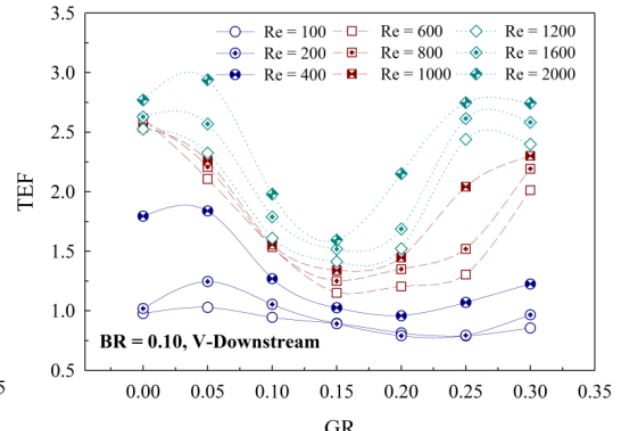

(b)

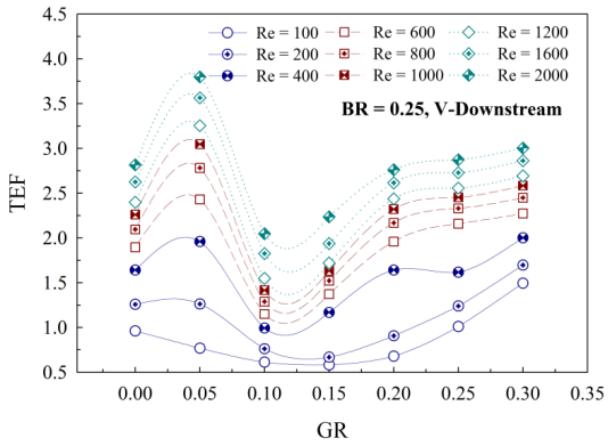

(e)

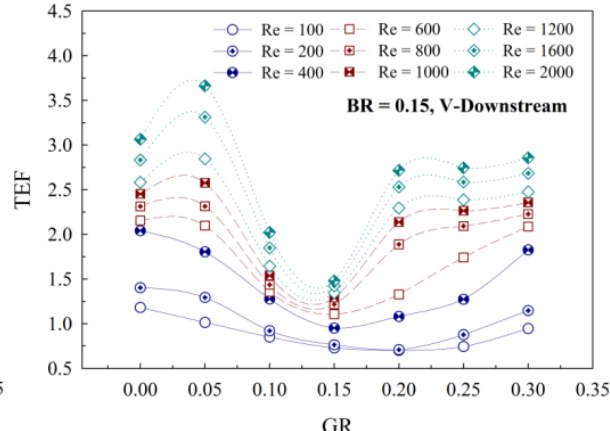

(c)

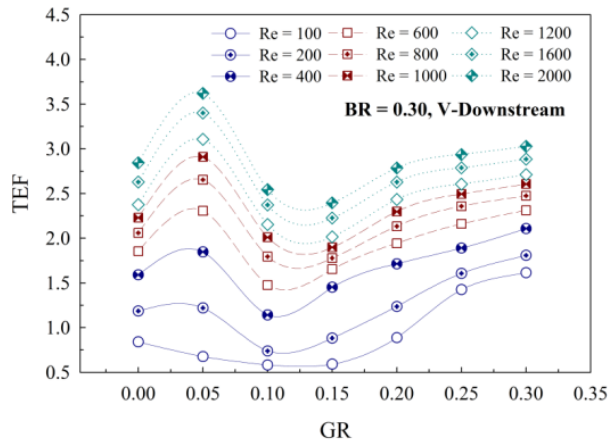

(f)

Fig. 23 TEF vs GR for V-Downstream of (a) $B R=0.05$, (b) $B R=0.10$, (c) $B R=0.15$, (d) $B R=0.20$, (e) $B R=0.25$ and (f) $B R=0.30$.

The present of the gap spacing between the V-orifice and the channel helps to reduce the pressure loss in the test channel and also helps to increase the turbulent mixing of the fluid flow. However, the large gap spacing is the reason for the reduction of the heat transfer rate due to the decrease of the vortex strength.
The optimum gap spacing ratio for both arrangements is around $5 \%(\mathrm{~g} / \mathrm{H}$ or $\mathrm{GR}=0.05)$ when considering the heat transfer rate and thermal performance enhancement, except for $\mathrm{BR}=0.15$ and 0.20 of $\mathrm{V}$ Upstream arrangement, which found the best thermal performance at $\mathrm{GR}=0$ or no gap spacing. 


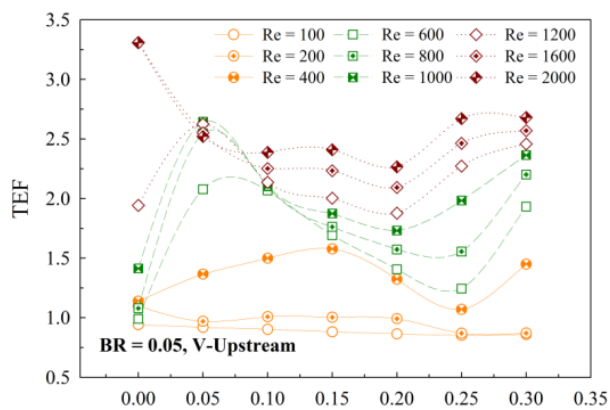

GR

(a)

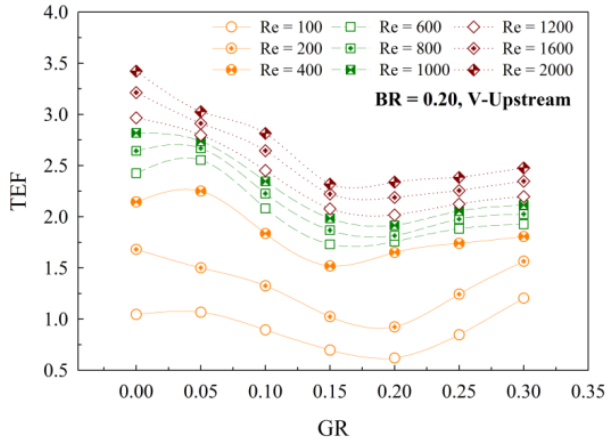

(d)

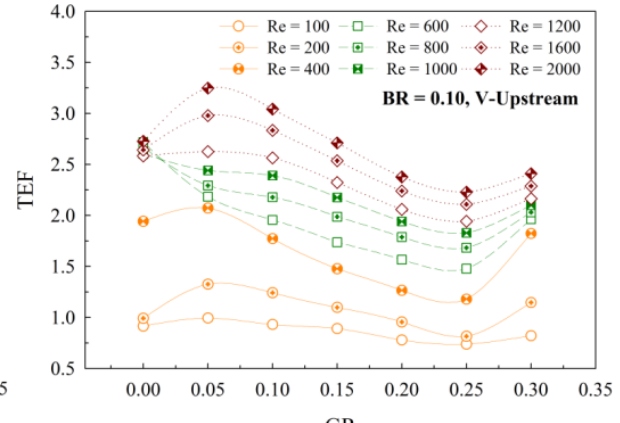

GR

(b)

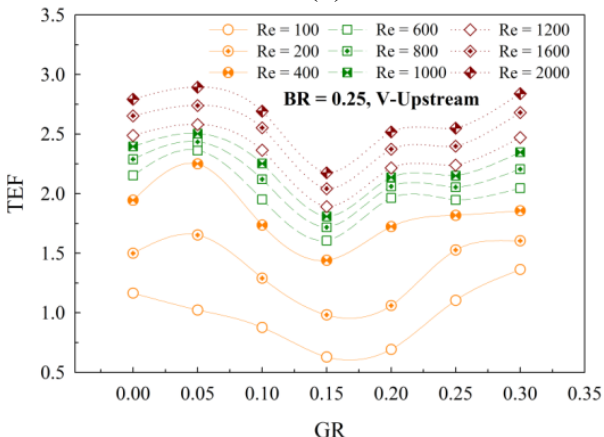

(e)

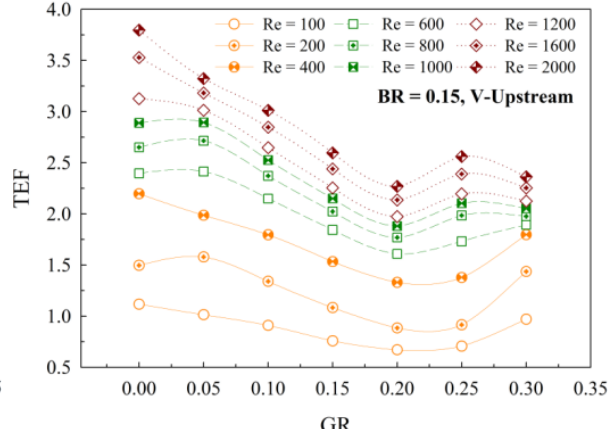

(c)

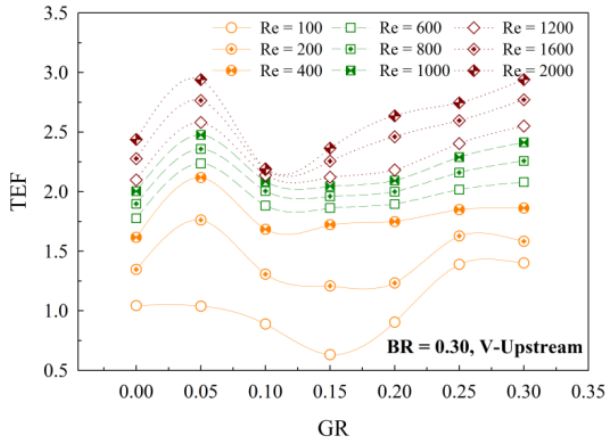

(f)

Fig. 24 TEF vs GR for V-Upstream of (a) $B R=0.05$, (b) $B R=0.10$, (c) $B R=0.15$, (d) $B R=0.20$, (e) $B R=0.25$ and (f) $B R=0.30$.

\section{ACKNOWLEDGEMENTS}

The authors would like to acknowledge Assoc. Prof. Dr. Pongjet Promvonge for suggestions. This research was funded by College of Industrial Technology, King Mongkut's University of Technology North Bangkok (Grant No. Res-CIT0230/2019).

BR flow blockage ratio $(=\mathrm{b} / \mathrm{H})$

\section{NOMENCLATURE}

$\mathrm{b}$ orifice height, $\mathrm{m}$

$\mathrm{D}_{\mathrm{h}}$ hydraulic diameter of channel, $\mathrm{m}$

f friction factor

GR gap spacing ratio, $(=\mathrm{g} / \mathrm{H})$

g gap spacing, $m$

$\mathrm{H}$ channel height, $\mathrm{m}$

$\mathrm{h}$ convective heat transfer coefficient, $\mathrm{W} \mathrm{m}^{-2} \mathrm{~K}^{-1}$

$\mathrm{k}$ thermal conductivity, $\mathrm{W} \mathrm{m}^{-1} \mathrm{~K}^{-1}$

$\mathrm{Nu}$ Nusselt number $(=\mathrm{hDh} / \mathrm{k})$

$\mathrm{P}$ pitch spacing, $\mathrm{m}$

$\mathrm{PR}$ pitch ratio $(=\mathrm{P} / \mathrm{H})$

$\mathrm{p}$ static pressure, $\mathrm{Pa}$

Pr Prandtl number $(\mathrm{Pr}=0.707)$

Re Reynolds number

$\mathrm{T}$ temperature, $\mathrm{K}$

$\mathrm{u}_{\mathrm{i}} \quad$ velocity in $\mathrm{x}_{\mathrm{i}}$-direction, $\mathrm{m} \mathrm{s}^{-1}$

$\bar{u} \quad$ mean velocity in channel, $\mathrm{m} \mathrm{s}^{-1}$

\section{Greek letter}

$\alpha \quad$ flow attack angle, degree

TEF thermal enhancement factor $\left(=\left(\mathrm{Nu} / \mathrm{Nu}_{0}\right) /\left(\mathrm{f} / \mathrm{f}_{0}\right)^{1 / 3}\right)$

$\rho$ density, $\mathrm{kg} \mathrm{m}^{-3}$

\section{Subscript}

in inlet

0 smooth tube

pp pumping power

\section{REFERENCE}

Boonloi, A., 2014, "Effect of Flow Attack Angle of V-Ribs Vortex Generators in a Square Duct on Flow Structure, Heat Transfer, and
Performance Improvement," Modelling and Simulation in Engineering, Article ID 985612, 11 pages. http://dx.doi.org/10.1155/2014/985612

Boonloi, A., and Jedsadaratanachai, W., 2014, "Thermal Performance Analysis and Empirical Correlations for Laminar Forced Convection over 30॰ V-Baffled Square Channel," Advances in Mechanical Engineering, Article ID 930272, 16 pages.

http://dx.doi.org/10.1155/2014/930272

Boonloi, A., and Jedsadaratanachai, W., 2016, "Numerical Investigation on Turbulent Forced Convection and Heat Transfer Characteristic in a Square Channel with Discrete Combined Vbaffle and V-orifice," Case Studies in Thermal Engineering, 8, 226235.

https://doi.org/10.1016/j.csite.2016.07.003

Jedsadaratanachai, W., and Boonloi, A., 2014, "Effects of Blockage Ratio and Pitch Ratio on Thermal Performance in a Square Channel with $30^{\circ}$ Double V-baffles," Case Studies in Thermal Engineering, 4, 118-128.

https://doi.org/10.1016/j.csite.2014.08.002

Jedsadaratanachai, W., Jayranaiwachira, N., and Promvonge, P., 2015, "3D Numerical Study on Flow Structure and Heat Transfer in a Circular Tube with V-baffles," Chinese Journal of Chemical Engineering, 23, 342-349.

https://doi.org/10.1016/i.cjche.2014.11.006

Kumar, R., Chauhan, R., Sethi R., and Kumar, A., 2017a, "Experimental Study and Correlation Development for Nusselt number and Friction Factor for Discretized Broken V-pattern Baffle Solar Air Channel," Experimental Thermal and Fluid Science, 81, 56-75. https://doi.org/10.1016/j.expthermflusci.2016.10.002

Kumar, R., Sethi, M., Chauhan, R., and Kumar, A., 2017b, "Experimental Study of Enhancement of Heat Transfer and Pressure Drop in a Solar Air Channel with Discretized Broken V-pattern Baffle," Renewable Energy, 101, 856-872.

https://doi.org/10.1016/j.renene.2016.09.033 
Kumar, R., Kumar, A., Chauhan, R., and Sethi, M., 2016, "Heat Transfer Enhancement in Solar Air Channel with Broken Multiple Vtype Baffle," Case Studies in Thermal Engineering, 8, 187-197. https://doi.org/10.1016/j.csite.2016.07.001

Kumar, S., Kothiyal, A.D., Bisht, M.S., and Kumar, A., 2019, "Effect of Nanofluid Flow and Protrusion Ribs on Performance in Square Channels: an Experimental Investigation," Journal of Enhanced Heat Transfer, 26(1), 75 - 100.

https://doi.org/10.1615/JEnhHeatTransf.2018026042

Li, J.L., Tang, H.W., and Yang, Y.T., 2018, "Numerical Simulation and Thermal Performance Optimization of Turbulent Flow in a Channel with Multi V-shaped Baffles," International Communications in Heat and Mass Transfer, 92, 39-50.

https://doi.org/10.1016/j.icheatmasstransfer.2018.02.004

Patankar, S.V., Liu, C.H., and Sparrow, E.M., 1998, "Fully Developed Flow and Heat Transfer in Ducts having Streamwise-periodic
Variations of Cross-sectional Area, ASME Journal of Heat Transfer, 98, 1109-1151.

https:// doi:10.1115/1.3450666

Promvonge, P., 2010, "Heat Transfer and Pressure Drop in a Channel with Multiple $60^{\circ}$ V-baffles," International Communications in Heat and Mass Transfer, 37, 835-840.

https://doi.org/10.1016/j.icheatmasstransfer.2010.04.003

Promvonge, P., and Kwankaomeng, S., 2010, "Periodic Laminar Flow and Heat Transfer in a Channel with $45^{\circ}$ Staggered V-baffles," International Communications in Heat and Mass Transfer, 37, 841-849. https://doi.org/10.1016/j.icheatmasstransfer.2010.04.002

Promvonge, P., Jedsadaratanachai, W., Kwankaomeng, S., $\quad$ and Thianpong, C., 2012, "3D Simulation of Laminar Flow and Heat Transfer in V-baffled Square Channel," International Communications in Heat and Mass Transfer, 39, 85-93.

https://doi.org/10.1016/j.icheatmasstransfer.2011.09.004 